\title{
PRACTICAL ASPECTS OF FUNDAMENTAL
}

\section{RESEARCH IN THERMIONIC CONVERSION}

Progress Report

Ned S. Rasor and Edward J. Britt

Rasor Associates, Inc. 200 Tait Road

Dayton, Ohio 45429

July 1, 1972 - August 31, 1973

PREPARED FOR THE U.S. ATOMIC ENERGY COMMISSION

UNDER CONTRACT NO. AT(11-1)-2263 


\section{DISCLAIMER}

This report was prepared as an account of work sponsored by an agency of the United States Government. Neither the United States Government nor any agency Thereof, nor any of their employees, makes any warranty, express or implied, or assumes any legal liability or responsibility for the accuracy, completeness, or usefulness of any information, apparatus, product, or process disclosed, or represents that its use would not infringe privately owned rights. Reference herein to any specific commercial product, process, or service by trade name, trademark, manufacturer, or otherwise does not necessarily constitute or imply its endorsement, recommendation, or favoring by the United States Government or any agency thereof. The views and opinions of authors expressed herein do not necessarily state or reflect those of the United States Government or any agency thereof. 


\section{DISCLAIMER}

Portions of this document may be illegible in electronic image products. Images are produced from the best available original document. 


\title{
PRACTICAL ASPECTS OF FUNDAMENTAL RESEARCH IN THERMIONIC CONVERSION
}

\author{
Progress Report
}

Ned S. Rasor and Edward J. Britt

Rasor Associates, Inc.

200 Tait Road

Dayton, Ohio 45429

July 1, 1972 - August 31, 1973

\section{PREPARED FOR THE U.S. ATOMIC ENERGY COMMISSION UNDER CONTRACT NO. AT(11-1)-2263}

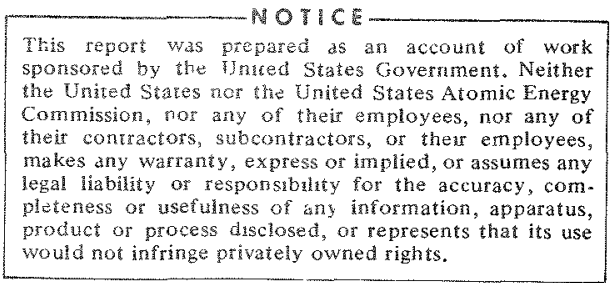


TABLE OF CONTENTS

\author{
ABSTRACT \\ I. INTRODUCTION \\ II. SUMMARY AND CONCLUSIONS \\ III. PRELIMINARI EVALUATION OF THERMIONIC TOPPING OF CENTRAL \\ STATION PONER FLANTS \\ IV. APPARATUS FOR FIXPLORING CONVERTER INNOVATIONS \\ V. CYINDRICAL DIODE WITH NIOBIUM EMITTER \\ VI. CUIINDRICAL DIODE WITH PLATINUM EMITITER \\ VII. ELECTRODE TECHNOLOGY
}

NOTE:

Each of the above sections is self-contained, having its ow references and figures at its end, and its own pagination. 


\begin{abstract}
This report describes the first year of continuation by the AEC of a project initiated and previously sponsored jointly by the AEC and the Office of Naval Research. During the reporting period a system was constructed for testing advanced cylindrical cesium-vapor thermionic converters with indirectly heated emitters. Initial testing of a cylindrical diode with a platinum-clad niobium emitter in pure cesium vapor showed that pulse enhancement could not be obtained with forward pulses as in previous inert gas pianar diodes, but the expected enhancement was obtained for reverse pulses. During testing, the arc drop in the unpulsed ignited mode of this converter gradually disappeared. This highly favorable result is tentatively thought to have occurred due to a new type of discharge occurring in a cavity formed by movement of the platinum cladding. A demountable cesium vapor system was also constructed for expanding the exploration of advanced converter con figurations previously perfomed in an inert gas system. A preliminary evaluation of thermionic topping of large electric power plants was performed to illustrate the significance of advanced converter performance in a remoriented general thermionic conversion program. A sumary of basic electrode requirements for advanced converter operation is also included.
\end{abstract}




\section{INTRODUCTION}

This project is a continuation of work initiated and previously sponsored jointly by the U.S. Atomic Energy Commission and the Office of Naval Research under Contract NOOO14-70-C-0252. A detailed synopsis of the past work and its objectives was included in the Final Report (NSR-1-4) for that contract. The overall objective of the previous work was to demonstrate that fundamental improvements in thermionic converter performance were possible which could substantially increase the performance of the thermionic reactor systems then being developed, and to assist in the engineering development of such systems through practical application of basic converter physics. This objective and the related activities characterized the work performed during the first half of the reporting period.

However, at mid-year the entire thermionic space reactor development program toward which this project was in technical support was abruptly terminated, with the likely prospect of our project also being terminated within a few months. As a result, the activities in our project which were in direct support of converter testing and design elsewhere in the program were immediately discontinued, and the construction of a test system for future exploration of new converter concepts was suspended. It was decided to concentrate, in the remaining short time, on the practical demonstration of pulse-enhanced converter operation, which our previous exploratory work had shown to the potentially useful. In addition, we emphasized evaluation of how the primary objective of our project, i.e. advanced thermionic converter performance, might make thermionic conversion practical for applications having high priority in the new national energy program, e.g. central. electric power systems.

It was subsequently decided to continue our project on the following basis:

Preliminary System Analysis - Emphasis will be on terrestial applications, where fuel conservation and costs are dominant. The results will be primarily in parametric form, rather than for a fixed design, such as to identify the relative importance of various potential advances in converter performance.

Basic Converter Characterization - The phenomenological description of elementary diode converter operation will be extended to include more advanced configurations and modes of operation.

Advanced Converter Demonstration - Attention in the experimental program will now be given exclusively to basic exploration and demonstration of 
advanced converter configurations and modes of operation. As shown schematically in Fig. I-I, tests will proceed through an exploratory phase in a demountable test vehicle, a demonstration phase in an optimized fixed-parameter test converter, and an eventual reduction to engineering practice of the most favorable concept in a converter module for a practical system.

Surface Physics - Electrode surfaces which meet the requirements of advanced converter electrodes will be developed and characterized.

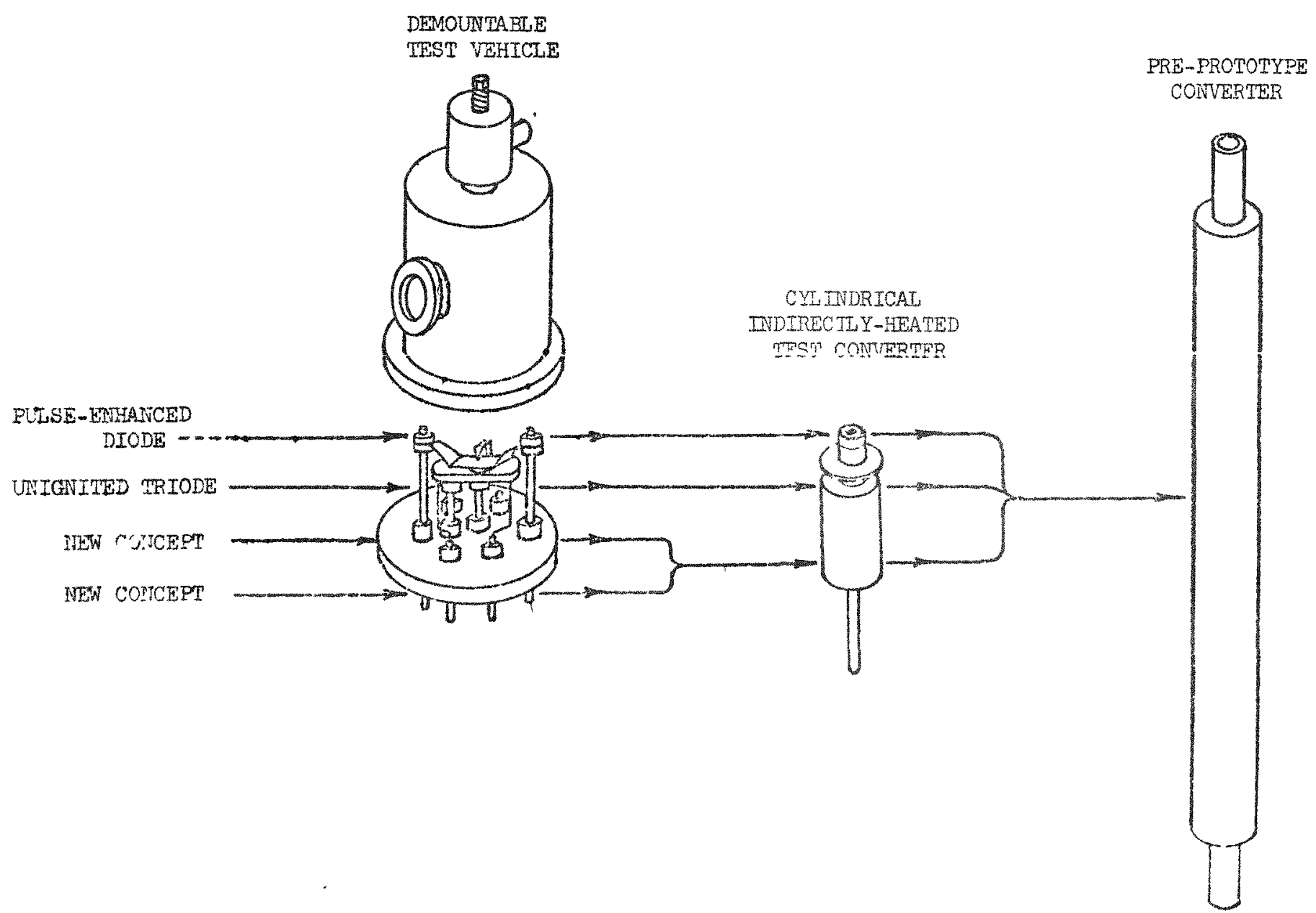

Fig. I-1. Strategy for advanced converter testing. 


\section{SUMMARY AND CONCLUSIONS}

A. Preliminary Evaluation of Thermionic Topping of Electric Power Plants

Summary. The present state of basic knowledge and engineering development of the thermionic converter, and recognized means for substantial performance improvements, are briefly summarized. The performance and practical utilization of a thermionic/steam topping system is considered for existing and advanced generations of converter performance. The trade-offs among heat source temperature (materials capability), converter performance and capital cost are expressed parametrically.

Conclusions. If sufficient attention is given to presently achievable improvements in converter performance, the themionic topping of electric power plants can become technically and economically feasible. Thermionic topping appears to merit at least as much consideration as MHD topping.

\section{B. Apparatus for Exploring Converter Innovations}

Summary. A demountable test vehicle for exploration of advanced converter configurations and modes of operation is described. This system was constructed but was not placed in operation during this reporting period because of the uncertainty of project continuation. A system was also constructed for operation of cyljndrical converters to demonstrate advanced modes of converter operation under more practical constraints. Such tests were initiated during this period.

Conclusions. These test systems and the associated instrumentation are available for continuation of the work of the project.

C. Test Results on a Cylindrical Converter With a Platinum-Niobium Finitter

Summary. Initial testing of the system, using a cylindrical cesium vapor diode with a niobium emitter, verified the expected performance of the system and instrumentation. The niobium emitter was then clad with a platinum sleeve. The resulting performance was initially as expected in the ignited mode, but no pulse-enhancement could be obtained with forward pulsing. Reverse pulsing gave enhancement with the output and pulse-power requirement expected for pure cesium vapor. During these tests the arc drop in the unpulsed ignited mode gradually became smaller, until eventually operation was being obtained without any apparent arc drop. Diagnostic procedures failed to find any measurement error which might be responsible for this result. Upon disassembly of the diode, it was found that the platinum emitter sleeve had moved, forming a cylindrical carity at one end of the diode.

Conclusions. Although the inability to obtain pulse-enhancement with forward puises in a cylindrical diode is not understood, tho successful reverse pulsing indicates that tests to verify the expectord higher performance with a Xe-Cs mixture should proceed. The molle of 
operation responsible for the observed elimination of the are trop $i:$

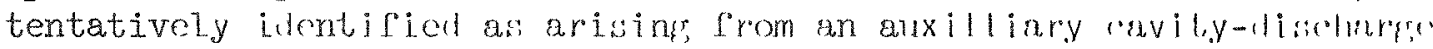
driven by the large contact potential differenow bolwen platimum and niobium portions of the emitter. If subsequent tests confirm the existence of this "hybrid" mode of diode operation, it could be a substantial advancement in thermionic conversion technology, leading to early availability of 2 nd generation performance.

\section{Electrode Technology}

Summary. The general emitter requirements for optimum operation of advanced types of thermionic converters are defined. Several types of surfaces appear to be capable of satisfying or exceeding these requirements. Available data indicate that the most favorable surfaces are Langmuir's atomic oxygen layer on tungsten, elementary platinum, and oxygen dispensed onto tungsten, in that order. A formalism for analytical description of the CS-O-W system is outlined.

Conclusions. It appears that the technology and basic understanding of emitters for advanced thermionic converters are ready for systematic reduction to practice.

The Principal Investigator, Dr. Ned S. Rasor, devoted approximately $55 \%$ of his time to this project during the reporting period. It is anticipated that he will spend approximately this same fraction of his time during the current term. 
III. PRELIMINARY EVALUATION OF THERMIONIC TOPPING

OF CENTRAL STATION POWER PLANTS

The material in this Section was prepared early this year, after announcement of the termination of the thermionic reactor space power program. Its purpose was to acquaint planners of the expanding U.S. energy program with the potential significance of the work in this project relative to commercial electric power production.

Because this summary presentation was intended primarily for use by non-specialists, it includes an elementary introductory summary. Also, in order to clearly convey the major conceptual aspects for planning purposes, the presentation is concise and graphic without analytical support and qualification. However, the analytical basis for the quantitative conclusions is included as an addendum in this report.

In the continuation of this project, a major objective is to perform a more detailed and comprehensive analysis of the topping system and other terrestial applications. This will include identification of the most attractive system concepts, and performance and cost analyses of specific preliminary system designs. The material in this section therefore should be considered only as a brief, approximate introductory outline for such a design study. 


\section{PROSPECTS FOR \\ THERMIONIC TOPPING OF \\ CENTRAL STATION POWER PLANTS}

\section{SUMMARY AND CONCLUSTONS}

Definition - The thermionic converter is an electron tube which converts heat directly into electrical power. It is a new member of the family of gas discharge power tubes which are widely used in the electrical power industry to transform and control electrical power at megawatt levels.

Status - Development has concentrated almost entirely on the type of thermionic converter suitable for large space nuclear power systems, which inherently require high temperature operation. High performance nuclear-thermionic fuel element assemblies of this type have been developed in the U.S.; a 10 kilowatt thermionic nuclear reactor is under construction in France; and a 10 kilowatt thermionic reactor has been in operation in the USSR since 1970.

Potential - Advanced types of thermionic converters have been demonstrated in the laboratory which are potentially capable of efficient operation at temperatures low enough for use in advanced central station power plants.

Topping Cycle - By modifying the steam generator, thermionic conversion can be used for topping steam power plants. Preliminary analysis indicates that overall thermal efficiencies of 50 to $60 \%$ are potentially obtainable, and that capital costs per kilowatt can be competitive with conventional systems.

Thermionics $V / s$ MHD - A comparison of thermionic/steam and MHD/steam topping systems indicates that the thermionic system is comparable in projected cost and overall plant efficiency with projections for the MHD system. However, the thermionic system can operate at substantially lower temperatures and is considerably less complex.

Because of the inherent modularity of the thermionic system, its efficiency, performance and cost are nearly independent of size. Since these factors are strongly size dependent in the MHD system, the thermionic system has distinct advantages in development time and cost, and in operational flexibility and maintainability.

It is concluded that thermionic topping merits at least as much consideration as MHD topping. 
BACKGROUND

- The thermionic energy converter is an electron tube which converts heat directly into electrical power by themionic emission. Its modern period of development dates from about 1958, although the basic principles were understood many years before that.

- The spontaneous (naturally occurring) surface and plasma properties of the elementary cesium vapor diode yield converter performance that is nearly ideally suited for application in space power plants, which inherently require compactness and high temperature operation. As a result, almost all funding and development has been concentrated on this type of thexmionic converter, with considerable success. In the $U \mathrm{~S}$ several englneering prototype assemblies have been operated for more than a year without failure under the extremely difficult conditions inside a nuclear reactor, and an individual converter has been operating continuously for 5 years without degradation.

A full scale space-type themionic reactor (about 10 kilowatts electrical. output) was placed in operation 3 years ago in the USSR, and details of its many thousands of hours of operation have been reported at international meetings. Next year, the French expect to test a thermionic reactor prototype intended for undersea applications. A11 these developments employ the elementary (present generation) cesium diode converter.

- Other types of thermionic converters, capable of highly efficient operation at lower temperatures, have been demonstrated in laboratory models. Relatively little attention and support has been given to practical development of these types because of the successful development of the elementary cesium diode, which is satisfactory for space applications, and because of the difficulty of integrating advanced converters into the hostile nuclear environment. However, the basic techrology is now available for practical development of a new generation of thermionic converters to match the requirements of central power station application. 
BASIC IHERMTONIC CONVERTER

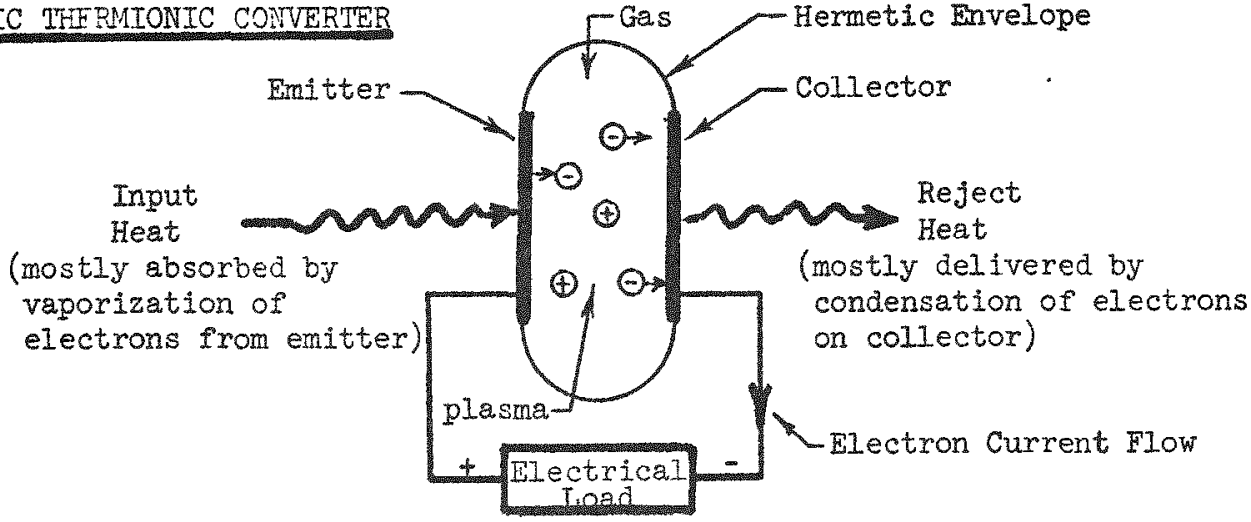

ELEMENTARY CESTUM VAPOR DIODE CONVERTER (Present Generation)

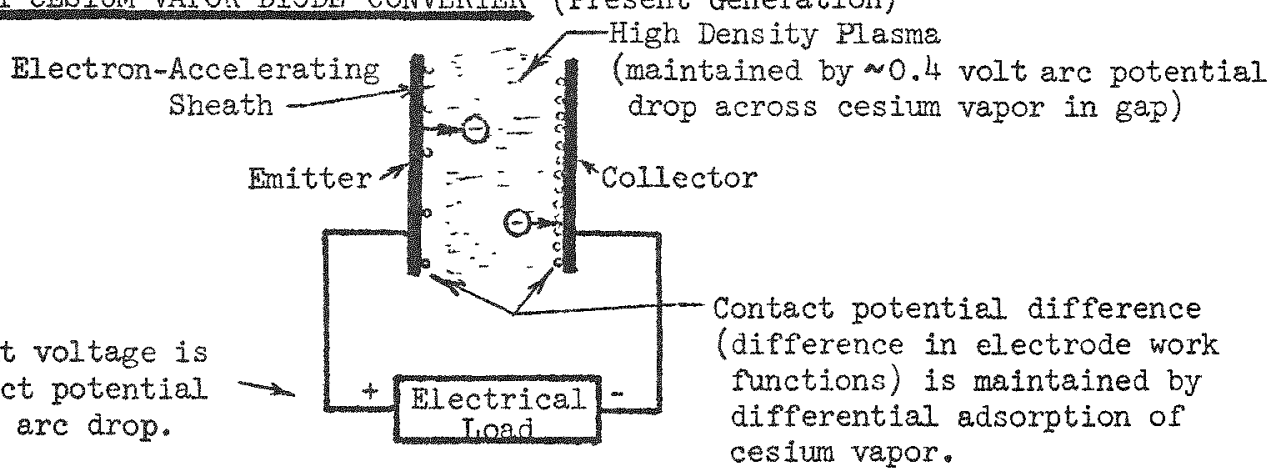

Output roltage is contact potential minus are drop. ceslum vapor

\section{ADVAITCED TYPES OF CONVERTERS (Future Generations)}

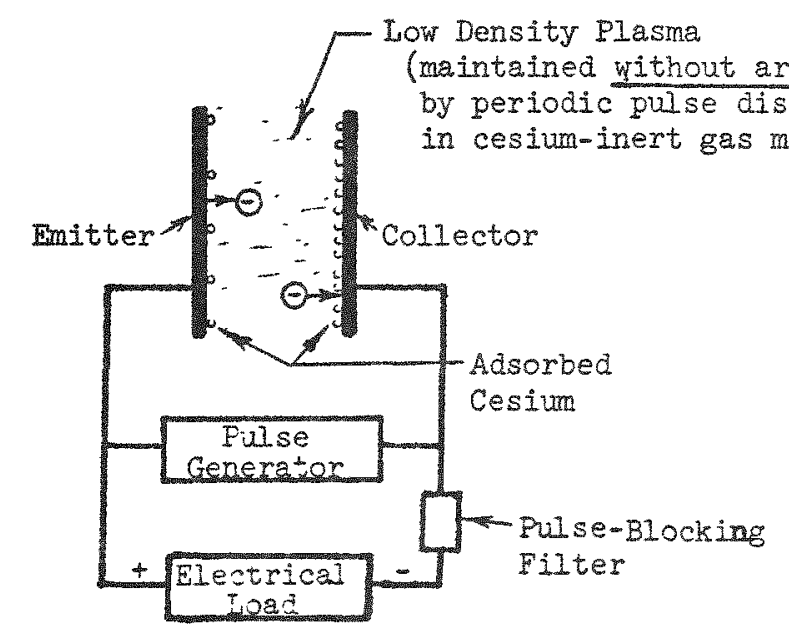

PUSE-ETEANCED DTODE CONVERTER

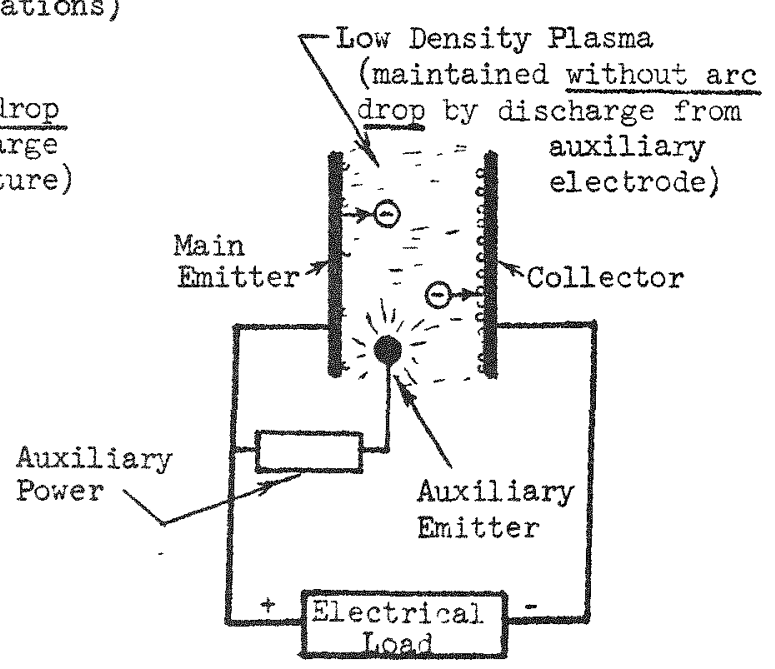

TRIODE COVVERTER 
- The performance of the thermionic converter depends critically on the electron energy losses in the plasma (i. e. the arc potential drop) and at the collector ( $i$. e. the collector work function).

- The electron energy losses which occur spontaneously in the cesium diode plasma are now well understood and have been minimized by past research. These minimized losses define the required operating temperatures and the electrical output of the present generation of engineering devices.

- Techniques have been demonstrated by which the plasma energy losses (and the arc drop) can be effectively eliminated in themionic converters. The lower cesium pressures associated with this type of operation require the use of a new generation of emitters trhose basic technolagy is alrcady known. The work function of present colleztors is somawhat lower under these conditions. These improvements permit significantly higher performance at lower temperatures.

- For applications which permit the use of lower heat rejection (collector) temperatures, the lower cesium pressures allow the use of collector surfaces known to have much lower work functions (e.g. the cesiun oxide surfaces used in commercial phototubes). If the use of such surfaces can be reduced to engineering practice in themionic converters, a further substantial increase in performance is obtainable at temperatures approaching those presentiy used in central station power plants. 
Electronic Energy Losses $=$ Arc Drop + Collector Work Eunction $=\phi_{c}^{\prime}$

Ist GENERATION PERFORMANCE: Characterized by $\phi_{c}^{\prime}=2.0 \mathrm{ev}$

(Present Tecinology) $\quad(0.4 \mathrm{ev}$ arc drop $+1.6 \mathrm{ev}$ collector work function)

Technology: Spontaneous plasma and surface properties in

the elementary cesium diode.

Status: Reduced to engineering practice

(10 Kwe system operating for 3 years in USSR).

$\frac{\text { 2nd GENERATTON PERFORMANCE: Characterized by } \phi_{\mathrm{c}}^{\prime}=\frac{1.5 \mathrm{ev}}{1.5 \mathrm{ev}}}{\text { (Near-Term Technology) }}$

(zero arc drop + $1.5 \mathrm{ev}$ collector work function)

Technology: Auxiliaxy plasma generation;

know emitter and spontaneous collector.

Status: Laboratory demonstration;

near term availability.

$3 r$ GENERATTON PERFORMANCE: Characterized by $\phi_{\mathrm{C}}^{\prime}=1.0 \mathrm{ev}$

(Foreseeable Goel) (zero arc drop $+1.0 \mathrm{ev}$ collector work function)

Technology: Auxiliary plasma generation;

known emitters and collectors.

Status: Projections based on known technology.
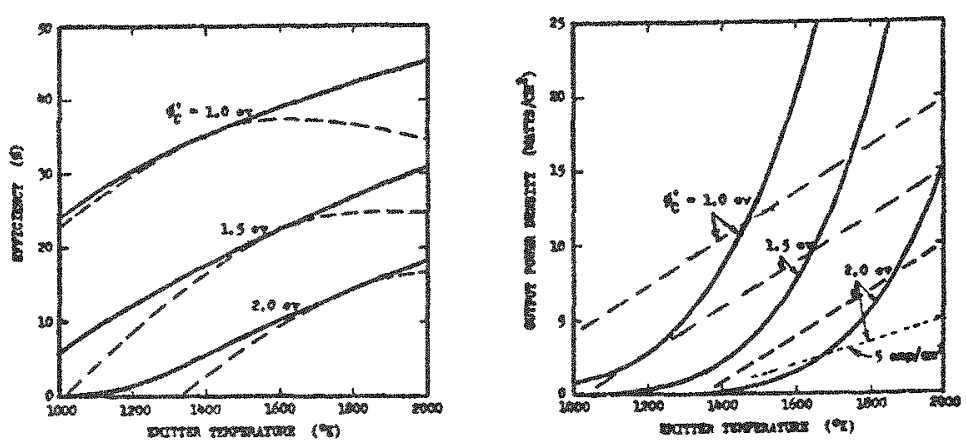

Thermionic converter perfomance as characterized by electronic energy losses parameter $\phi^{\prime}$. Solid lines are for maximum efficiency; dashed

Lines are for $10 \mathrm{app} / \mathrm{cm}^{2}$ outrut current density. 
- The emitter and collector regimes which are typical of the various generations of thermionic converters are as shown. The upper limit of each emitter regime corresponds to the approximate temperature at which maximum efficiency is obtained if the current density is limited to 10 amperes $/ \mathrm{cm}^{2}$. Such a current limit is typically necessary to avoid significant ohmic losses in the electrode structures. The lower temperature limit corresponds to the approximate temperature at which the output power begins to fall below an economically attractive level, as defined in the subsequent discussion of costs. The energy conversion efficiencies are listed to the right of the respective regime limits.

- Also shown is the temperature regime of modern steam plant operation. The energy conversion efficiencies associated with various degrees of superheat in such plants are listed to the left of this regime.

- The overall efficiencies of the thermionic/steam topping cycle, using the collector temperatures shown, are listed to the left of the respective emitter regime limits.

- The operating regimes for several potential heat transfer fluids for use in these temperature regimes is also shown. 


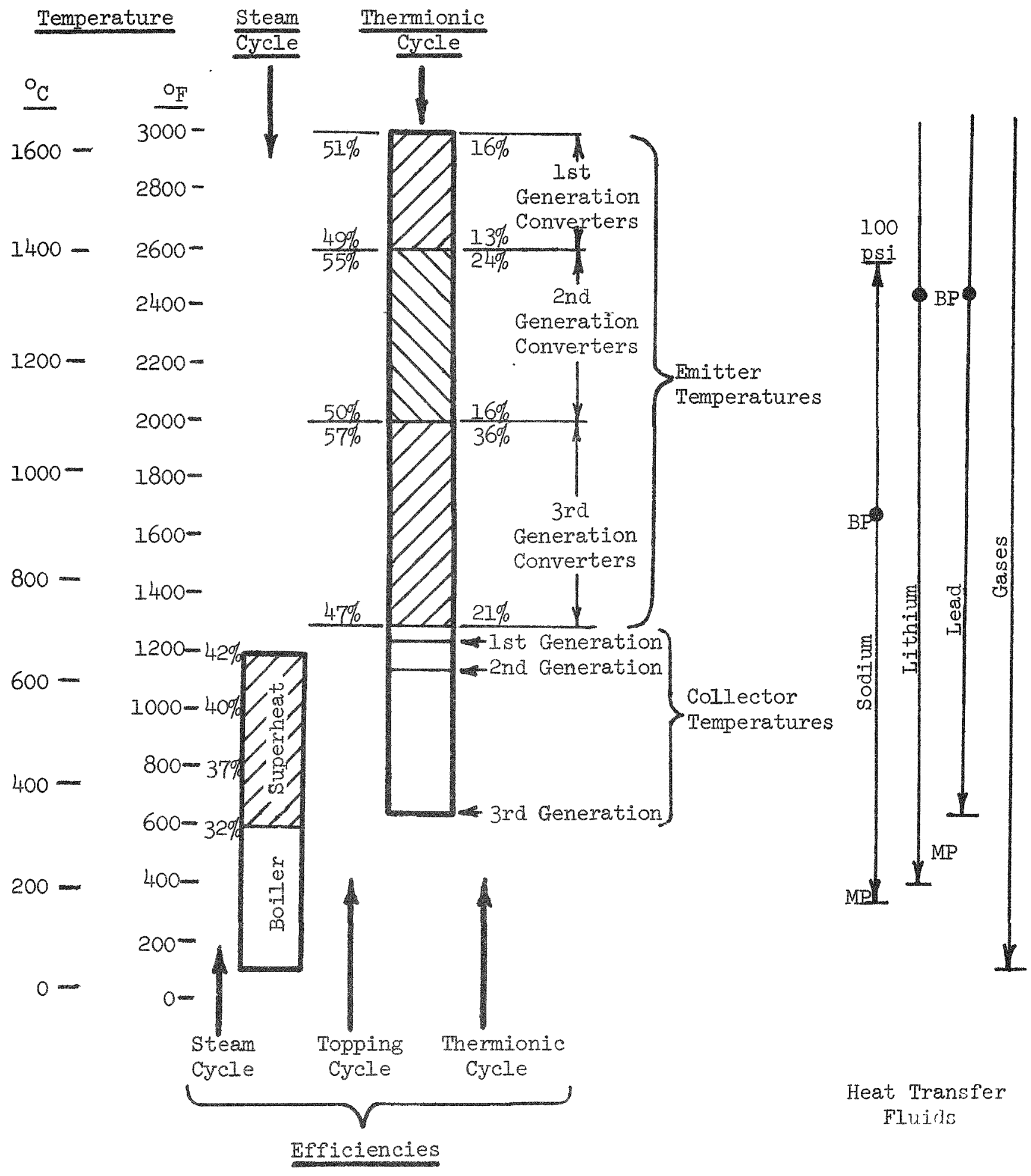


- For thermionic topping of central station power plants, the thermionic converters probably would be incorporated into the steam generator as shown. The boiler tubes become converter emitters which are enclosed in coaxial collector tubes. The space between these coaxial tubes communicates with cesium vapor plenums at each end. Electrons vaporized from the emitter tubes transfer heat from the hot fluid to the collector tubes for generation of steam. The electrical output power is obtained by connecting the emitter tubes with the collector tubes through an electrical load.

- The collector tubes can be constructed of the same material and operate at the same temperatures and pressures as the boiler tubes in a conventional steam generator. The emitter tubes must contain the low pressure fluid from the heat source, but they are completely isolated from the high pressure steam. Ceramic spacers can be used to maintain the gap between the emitter and collector tubes

It should be clear that the configuration can be reversed; i.e. the: collector tubes can be inside the emitter tubes. Also, the usual counterflow-tube and tube-in-shell alternatives exist as in conventional heat exchanger design. 
Hot Fluid from

Heat Source

(1iquid metal

or gas)

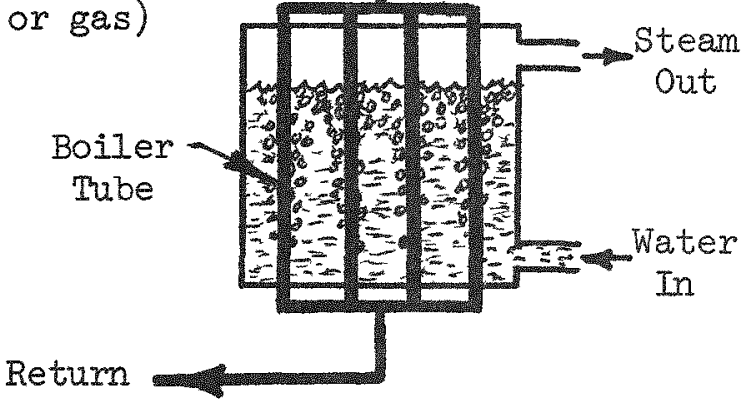

Conventional Steam Generator

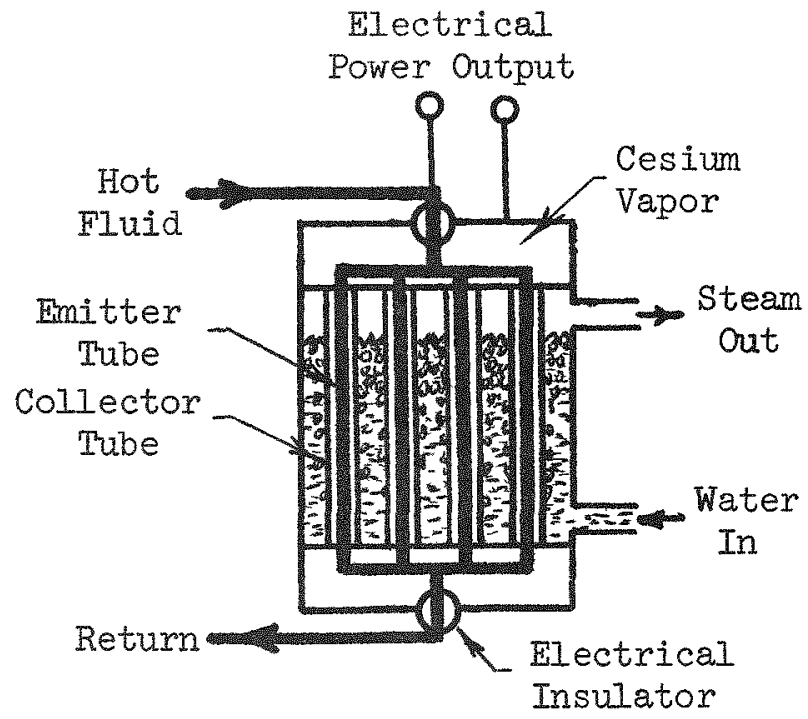

Thermionic Steam Generator (TSG)

Symbols
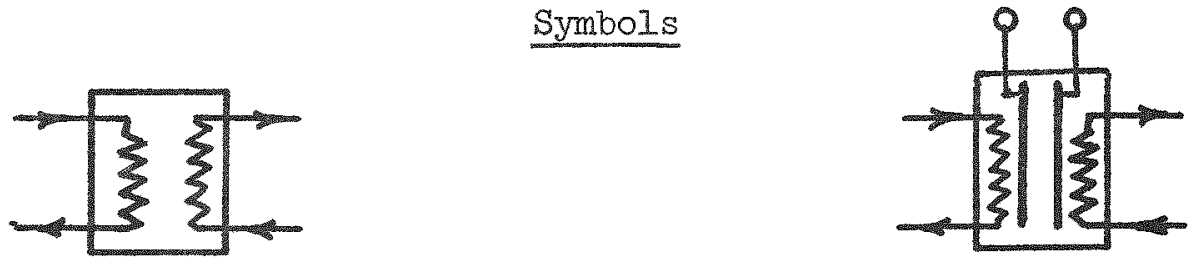

Typical

Cross Sections
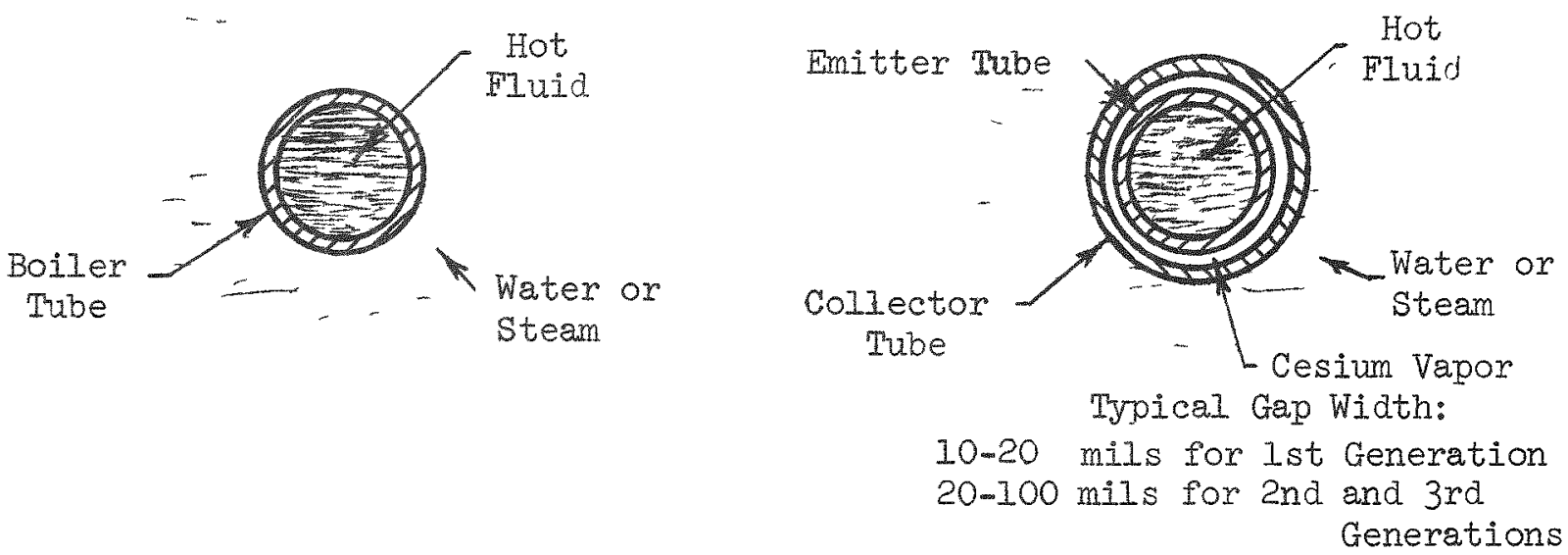
Conventional Steam Cycle

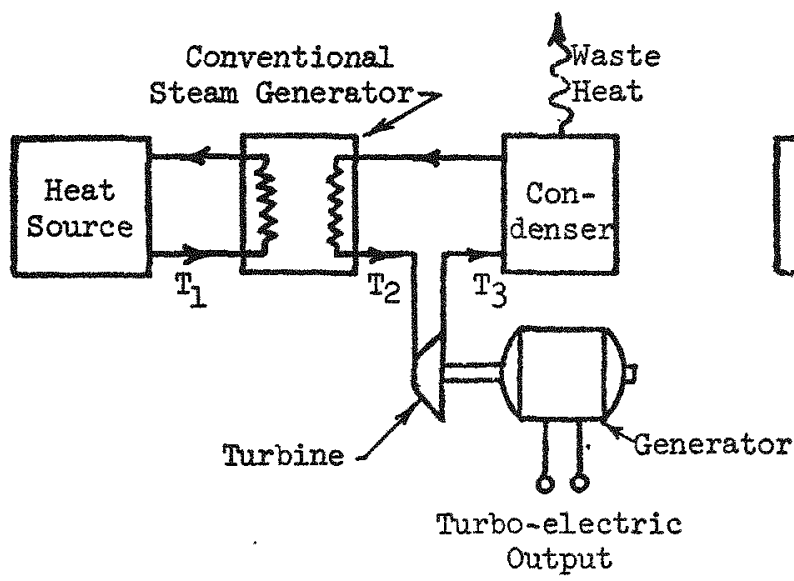

Thermionic/Steam Topping Cycle

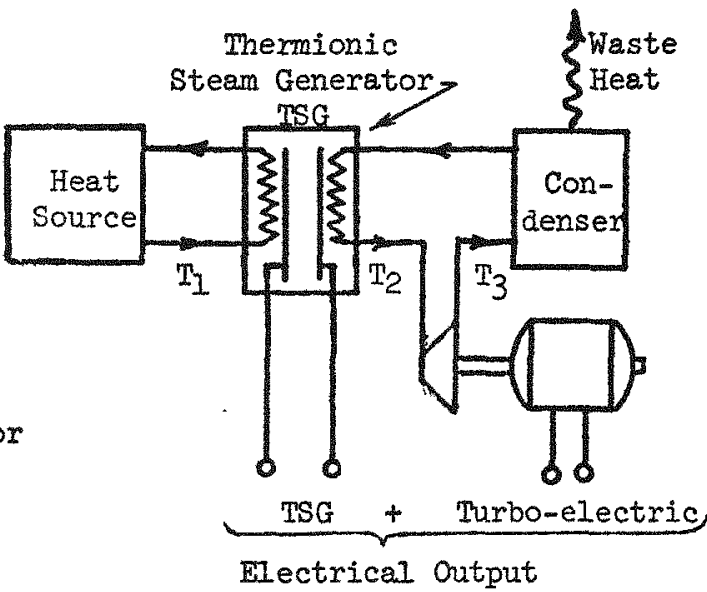

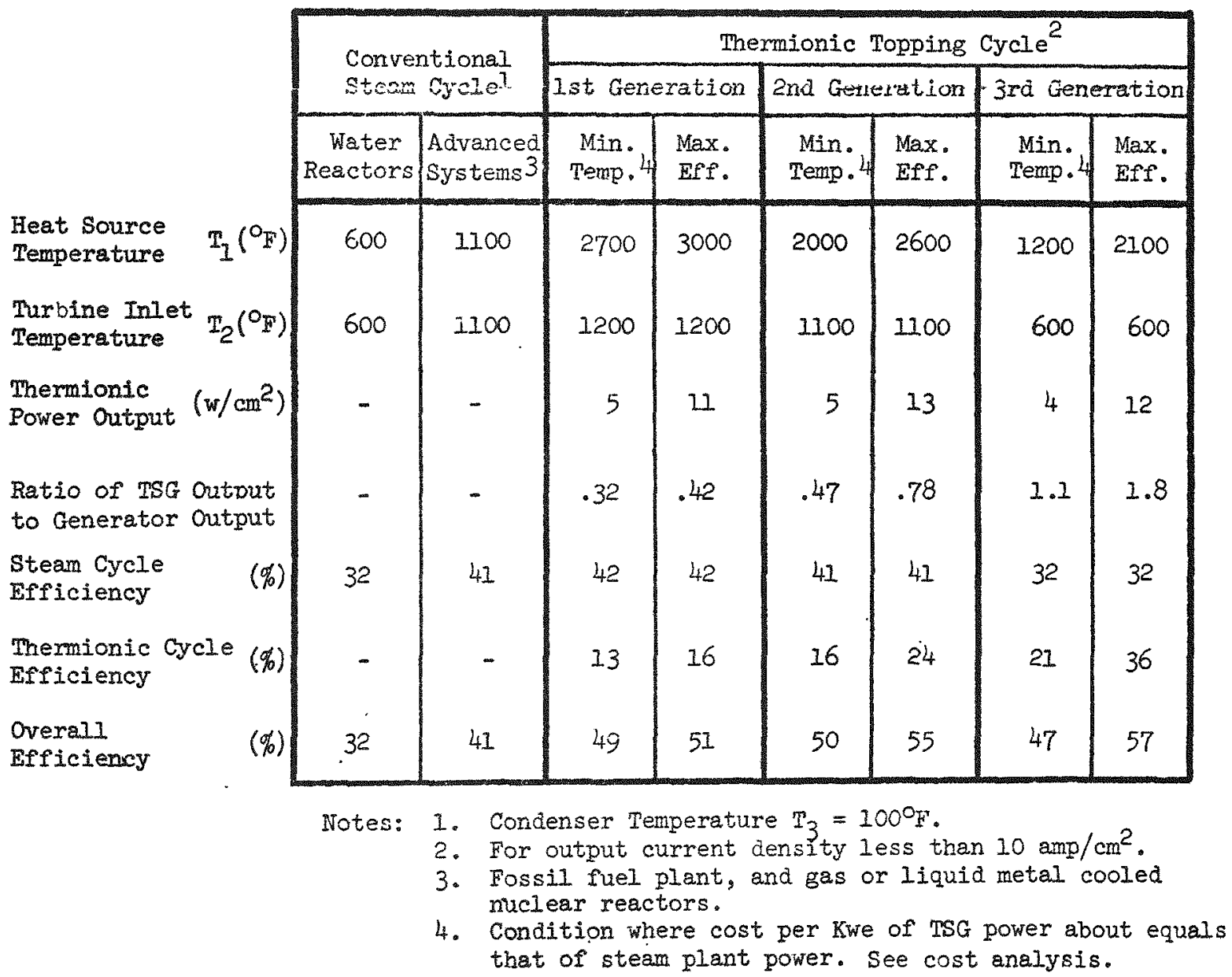


Direct Use of ISG Ontput by Local DC Consumers

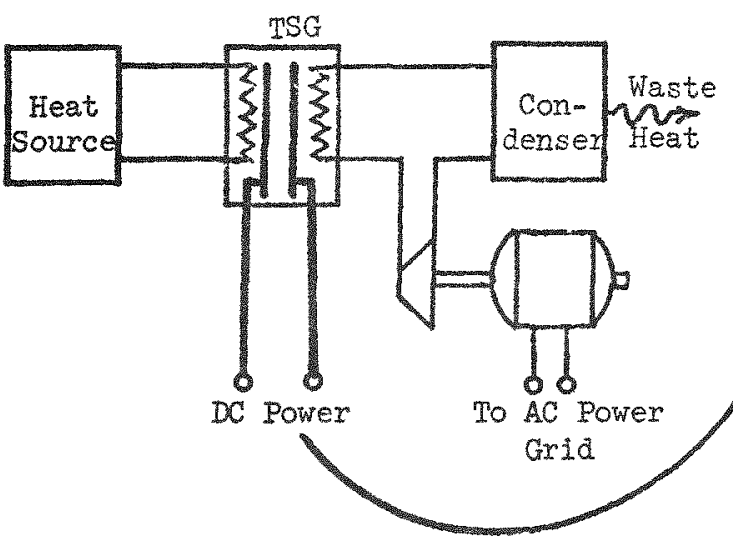

ISG Counling to Turbogenerator

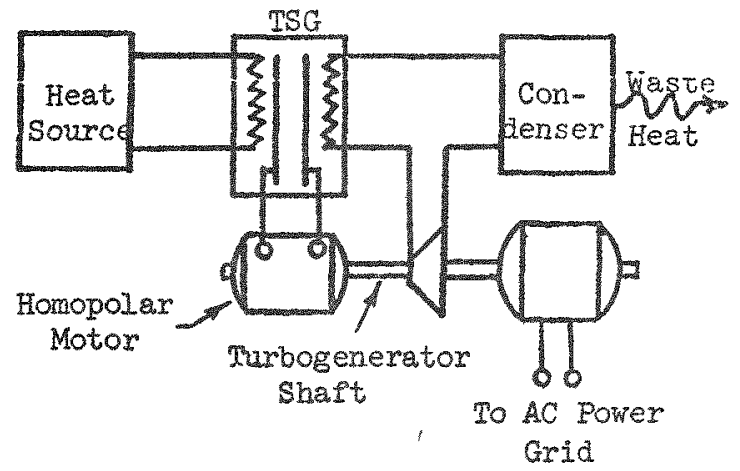

Inductive Coupling to $\mathrm{MSG}$

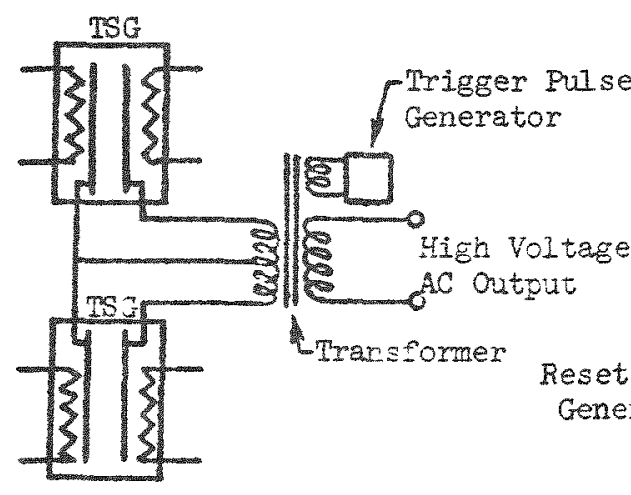

Push-Pull Ooeration
Motor-generator efficiencies in excess of $95 \%$ are available now. Recent advances have been made in homopolar motors through use of superconductors.

(Both methods have been demonstrated experimentally) 


\section{COST ESTIMATE}

A detailed TSG system design on which to base reliable costs does not exist yet. However, an estimate can be made based on existing fossil fuel and nuclear power plant costs:

\section{Steam Plant Cost}

Except for the costs of the steam generator and heat source (fumace or reactor), the remainder of the steam system should cost nearly the same as existing systems of the same output.

\section{Heat Source Cost}

The size and configuration of the fumace or reactor should be nearly unchanged. The primary additional cost of the heat source therefore would arise from higher cost materials and other such costs associated with higher temperature operation. Although detailed studies of such costs are needed, they probably are not a decisive factor in the total cost of the plant once the technology is developed.

\section{TSG Cost}

The ISG is essentially a modified conventional steam generator. The temperature required for the cost per kilowatt of TSG power to equal that of conventional steam plant power is given below as a function of the relative cost of the TSG. The minimum emitter temperatures cited in the previous pages are for a ISG cost of about 5 times the cost of a conventional steam generator, which is potentially achievable. Lower $15 G$ costs would substantially lower the required temperatures.

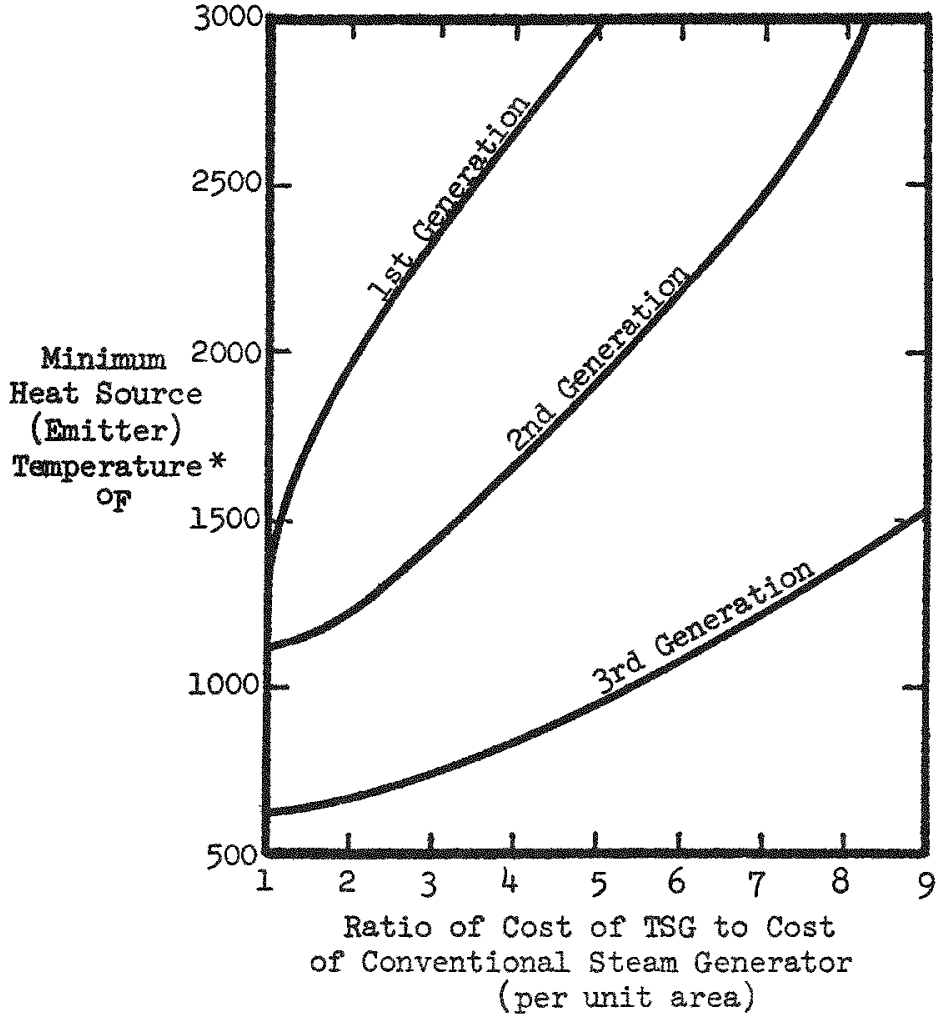

Based on:

Cost of conventional steam Generator $=\$ 10 / \mathrm{KW}$ thermal

Cost of conventional power plant $=\$ 200 / \mathrm{KW}$ electrical

Ave. heat flux

in conventional steam generator $=10 \mathrm{w} / \mathrm{cm}^{2}$ (output heat flux in the TSG is limited to this value)

* Temperature at wich \$/Kwe capital cost for ISG equals that for a conventional power plant. 
Nuclear Fineled IsG System

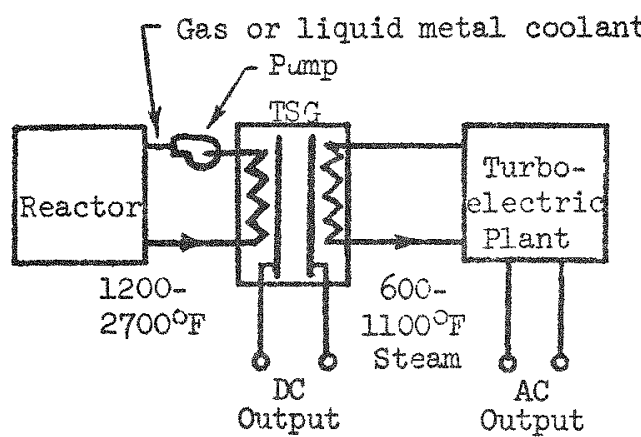

overall Efficiency $=50-60 \%$
Nuclear Tueled MHD/Steam System

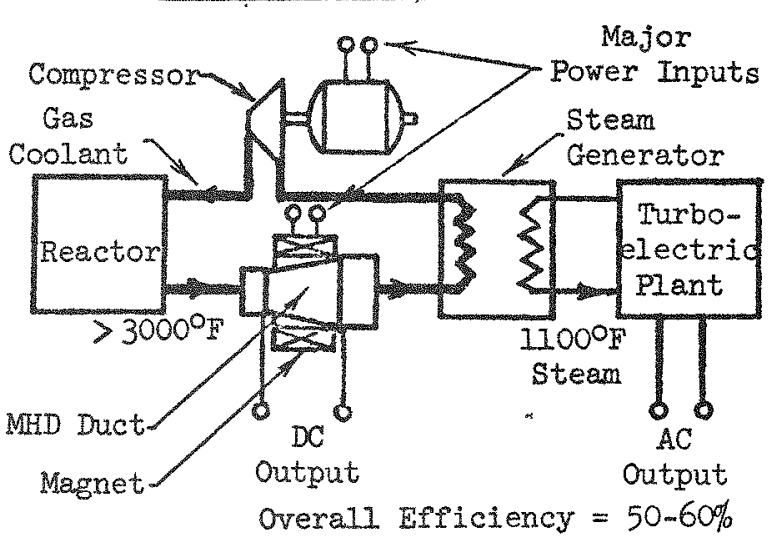

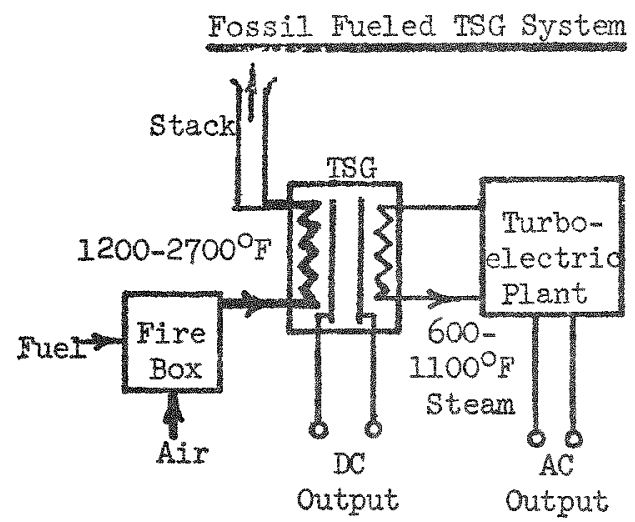

Overall Efficiency $=50-60 \%$

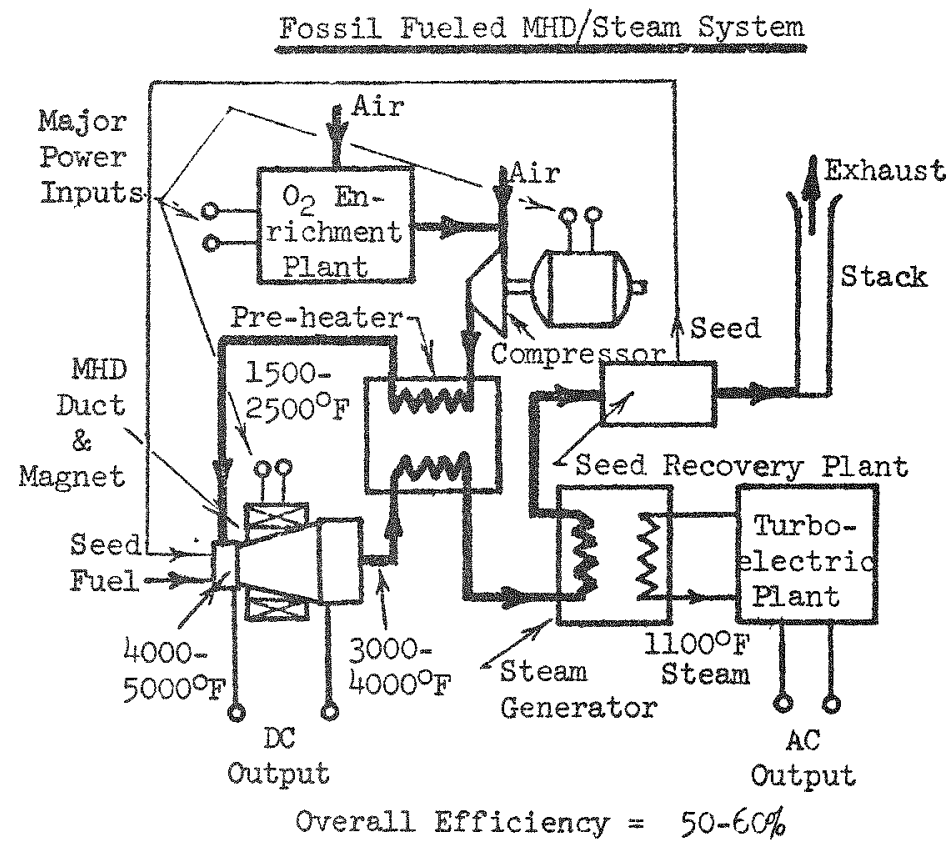

Fossil Fueled MHD/Steam System

COST COMPARISON

Several estimates 6 show that the capital cost per electrical kllowatt of an MHD/steam topping system should be about equal to that of a conventional steam power plant.

The conditions for the capital cost per electrical kilowatt of a themionic/steam topping system to equal that of a conventional steam power plant are show on the opposite page. 
ADDENDUM -

ANALYTICAL BASIS FOR CONCLUSIONS SUMMARIZED IN THE PROSPECTUS

\section{Thermionic Converter Performance Characterization}

A sumaxy description of the characterization of thermionic converter performance in terms of the effective collector work function $\phi_{\mathrm{c}}^{\prime}$, as shown on page III-6, is given in Reference 1. This characterization is most useful as a reasonably accurate approximation for preliminary estimates and for intuitive perspective, e.g. for defining performance objectives ("generations" or "milestones").

In this characterization, each value of $\phi_{c}^{\prime}$ refers to the performance of a reference ("ideal") converter having this value as its collector work function. The reference performance used here is that of a converter in which:

1. the collector current is given by the Richardson equation

$$
J=A T_{E}^{2} \exp \left(\frac{V+\phi_{C}^{2}}{k T_{E}}\right)
$$

2. the potential drop across and heat loss through the emitter lead are optimized for maximum efficiency;

3. heat transfer between the electrodes is only by the transported electrons and by thermal radiation (the effective net emissivity is that between two planar surfaces each having the emissivity of tungsten at the emitter temperature).

This reference performance is easily computed for given values of output voltage, emitter temperature and effective collector work function $\phi_{c}^{\prime}$. It is independent of emitter work function for $\phi_{\mathrm{E}} \leqslant V+\phi_{\mathrm{c}}^{\prime}$. Al though collector temperature can be included in this computation, its effect is negligible at sufficiently low collector temperatures, and therefore is not included in the reference performance. Descriptions and tabulated values of reference (ideal) converter performance, including the conditions for maximum efficiency at given emitter temperature and collector work functions, have been published. $2-5$

The reference performance corresponding to a value of the effective collector work function

$$
\phi_{c}^{*}=\mathrm{v}_{\mathrm{d}}^{p}+\phi_{\mathrm{c}}
$$


per se, represents the maximum converter performance obtainable in terms of the physically definable arc drop $V^{8}$ and true collector work function $\phi$. While this performance cannot be reached or exceeded in actual practice, it will be progressively approached as the many practical but unessential non-idealities are suppressed in practical applications. In order to have an invariant reference performance during this progression, these non-idealities are omitted from the reference performance.

In spite of the ideal nature of the reference performance as defined above, the associated $\phi_{c}^{\prime}$ can be used very effectively as a parameter to characterize the performance of real converters and their use in real systems. This results from the relative insensitivity of the converter performance to all variables except the emitter temperature $T_{\mathrm{E}}$ and the effective collector work function $\phi_{\mathrm{C}}^{\prime}$, because of their exponential relationship to converter output in Eq. III-1.

Non-idealities which tend to reduce the factor A from its ideal value $120 \mathrm{amp} / \mathrm{cm}^{2}-\mathrm{O}^{2}$ (i.e. non-uniform emitter surface, electron scattering, etc.) can be characterized to a very good approximation by a relatively small change in the effective value of $\phi_{c}^{\prime} e_{. g}$ a $50 \%$ reduction in output current $J$ resulting from such non-idealities corresponds to about a $0.1 \mathrm{ev}$ (about 5\%) change in $\phi_{\mathrm{c}}^{\prime}$. For example, Fig. III-I shows that the experimentally observed performance for Ist Generation converters with near-optimum cesium pressure (11OW- Nb) is quite accurately characterized by $\phi_{c}^{\prime}=2.0$ ev. However, independent measurements under these conditions give $V_{d} \approx 0.35 \mathrm{ev}$ and $\phi_{\mathrm{c}} \approx 1.55 \mathrm{ev}$, such that the effective coliector work function should be $\phi_{c}^{\prime} \approx 1.9$ ev in its strict interpretation as a physical quantity as in Eq. III-2. The O.I ev difference between this and the empirical value for $\phi_{c}^{\prime}$ presumably reflects the non-ideality of the experimental device, which arises primarily from electron scattering in that case. It may be seen, therefore, that $\phi_{c}^{\prime}$ is highly useful as a semi-empirical parameter for characterizing and interpreting observed device performance.

As a further example, Fig. III-I shows that the performance of a converter which requires above-optimum cesium pressure ( $100 \mathrm{~W}-\mathrm{Nb}$ ) is characterized by $\phi_{c}^{\prime}=2.1-2.3 \mathrm{ev}$. The $0.1-0.3 \mathrm{ev}$ increase in $\phi_{c}^{\prime}$ reflects the expected increases in both electron scattering and true collector work function which accompany high cesium pressures. Conversely, a $0.1-0.2$ decrease in the characteristic $\phi_{c}^{\prime}$ is observed when oxygen is added to the electrode surfaces, which substantially reduces the required cesium pressure. Also shown in Fig. III-I are operating points observed for the converter described in Section VI which apparently are characterized by $\phi_{c} \approx 1.5 \mathrm{ev}$. The implication is that the arc drop has been eliminated and that the true collector work function was less than $1.5 \mathrm{ev}$, which is consistent with other observed behavior of this device.

Finally, it should be pointed out that the effects of other 
non-idealities on the performance of practical devices and systems can be easily characterized by adding the associated potential drop to $\phi_{c}^{\prime}$. This includes additional potential drops in the plasma, across connectors and off-optimum leads, and through electrode structures. Similarly, the performance of an advanced converter with auxilliary ion generation can be characterized by including in $\phi_{c}^{\prime}$ the potential drop across an auxilliary power supply (in series with the load) which would be required to operate the ion source (e.g. a third electrode).

In summary, therefore, it can be seen that the use of the parameter $\phi_{c}^{\prime}$ to characterize the effect of converter performance in preliminary studies, such as for the topping application, is both fundamentaliy valid and useful. However, intensive converter research and detailed system analysis are required to accurately define the values of $\phi_{c}^{\prime}$ achievable at a given level of technology and within a given time period.

Data on Conventional Steam Plant and MHD Topping System

Data on the performance and cost of modern conventional steamturboelectric power plants and the MHD/steam topping system were obtained from Reference 6. Where ranges of performance and cost were given, an average value was chosen for use in the prospectus on thermionic/steam topping.

Derivation of Cost and Performance Relationships for the Thermionic/ Steam Topping System

Definitions

$Q_{i}=$ rate of heat input to entire system.

$Q_{S}=$ rate of heat input to steam system.

$P_{t}=$ electrical power output of thermionic steam generator (TSG).

$P_{S}=$ electrical power output of steam-turboelectric system.

$p_{t}=P_{t} / A=$ average electrical output power density of TSG.

$A=$ total emitter area $\approx$ total boiler area.

$q_{S}=$ average heat flux density in conventional steam generator.

$\eta_{t}=P_{t} / Q_{i}=$ overall efficiency of $\mathrm{TSG}$.

$\eta_{\mathrm{S}}=\mathrm{P}_{\mathrm{S}} / \mathrm{Q}_{\mathrm{S}}=$ overall efficiency of steam-turboelectric system.

$\mathrm{C}_{\mathrm{S}}=$ overall cost per electrical kilowatt output of a conventional steam-turboelectric plant.

$\mathrm{C}_{\mathrm{g}}=$ cost per thermal kilowatt of conventional steam generator.

$\mathrm{F}=$ ratio of cost of $\mathrm{ISG}$ to cost of conventional steam generator per unit area of each. 
Condition 1: The net cost of the TSG per electrical kilowatt of its output should not exceed the overall cost per electrical kilowatt output for a conventional steam-turboelectric power plant; i.e.

$$
\frac{F q_{S} C A-Q_{S} C_{g}}{P_{t}} \leq C_{S}
$$

Energy conservation in the TSG requires that $Q_{S}=Q_{i}-P_{t}$, which combined with Eq. III-3 and the foregoing definitions gives

$$
F \leq \frac{p_{t}}{q_{S}}\left(\frac{c_{S}}{c_{g}}+\frac{1}{\eta_{t}}-1\right)
$$

Condition 2: The average output heat flux density in the TSG should not exceed that in a conventional steam generator; i.e.

$$
\frac{Q_{S}}{A} \leq q_{S}
$$

which combined with Eq. III-3 gives

$$
E \leq \frac{\mathrm{C}_{\mathrm{S}} / \mathrm{C}_{\mathrm{g}}}{\frac{1}{\eta_{t}}-1}+1
$$

Condition 3: The output current density in the TSG should not exceed $10 \mathrm{amp} / \mathrm{cm}^{2}, 1 . e$.

$$
J \leq 10 \mathrm{amp} / \mathrm{cm}^{2}
$$

The restrictions imposed by Eqs. III- 4,6 and 7 can be used together with the reference performance plots on page III-6 to establish the minimum emitter temperature $T_{\mathbb{F}}$ for which these conditions are satisfied. The relationship thus defined between $T_{E}, F$ and $\phi_{c}^{\prime}$ is shown on page III-13 for typical values of conventional steam system parameters $\left(q_{S}=10 \mathrm{w} / \mathrm{cm}^{2}\right.$ and $\left.C_{S} / C_{g}=20\right)$. For these values the limitation in $\mathrm{Eq}$. III-5 is dominant over the entire region shown, i.e. the heat flux density in the TSG equals that in a conventional steam generator. Eq. III-6 therefore applies throughout since the current lensity is al ways less than $10 \mathrm{amp} / \mathrm{cm}^{2}$ due to this heat flux limitation. The 
temperatures shown therefore represent the approximate break-even point for capital cost of the thermionic topping cycle. A cost advantage and higher overall plant efficiency is obtained at higher temperatures, especially if the heat transfer limitation is relaxed (i.e. for $q_{s}>10$ watt $/ \mathrm{cm}^{2}$ ).

This plot shows the tradeoffs among the three principal considerations in the thermionic/steam topping cycle application.

1. Materials technology for which $\mathrm{T}_{\mathrm{E}}$ is a primary parameter;

2. Thermionic converter performance for which $\phi_{c}^{\prime}$ is a primary parameter;

3. TSG cost relative to that of a similar conventional power plant component, represented by the parameter $F$.

Through these parameters the planner can exercise judgment, according to his personal degree of optimism (or pessimism) in each, as to the extent and direction of effort required for practical utilization of the thermionic/steam topping system.

Some performance relationships used to obtain data for the table on page III-II are obtained as follows. The overall topping cycle efficiency is given by

$$
\eta_{0}=\frac{P_{t}+P_{s}}{Q_{i}}=\eta_{s}+\eta_{t}\left(I-\eta_{s}\right)
$$

The ratio of TSG electric power output to turboelectric output in the topping system is given by

$$
\frac{P_{t}}{P_{s}}=\frac{\eta_{t}}{\eta_{s}\left(1-\eta_{t}\right)}
$$

\section{SECTION III REFERENCES}

1. N.S. Rasor, Third Internl.Conf. on Thermionic Elect.Power Gen., Julich, Germany (June, 1972), Vol. 3, p 1027. Also appears as Section IX of our report NSR-I-4.

2. N.S. Rasor, Progress in Astronautics and Rocketry, Vol. 3, Academic Press, N.Y., 1961, p 155.

3. J. M. Houston, Advances in Electronics 17, 147(1962).

4. I.H. Ingold, J.Appl.Phys. 32, (1961)769.

5. A.Schock, J.Appl.Phys. 32, (1961)769.

6. "The U.S. Energy Problem", InterTechnology Corp. Report 645 to the National Science Foundation (Nov. 1971). 


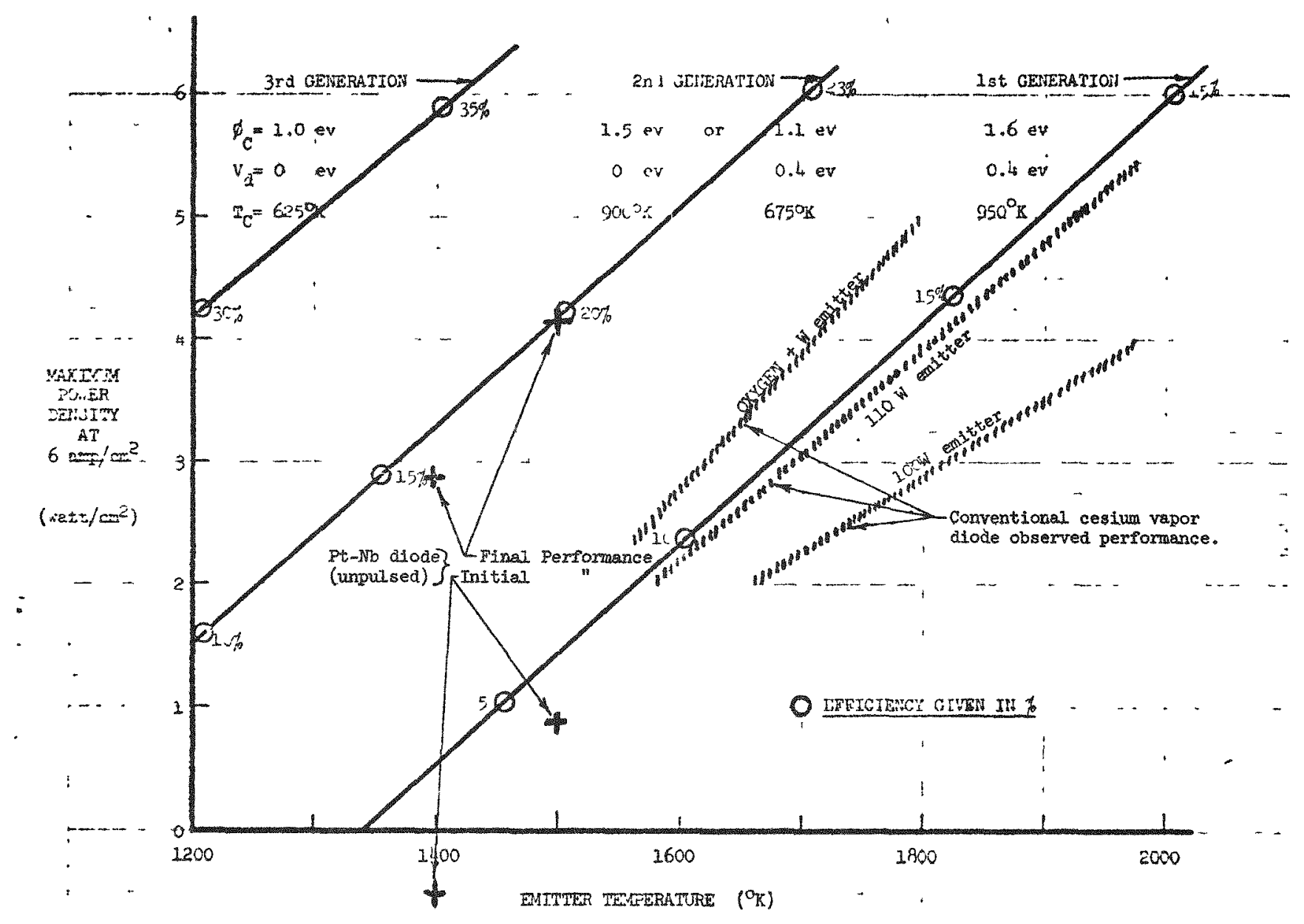

Fig. III-1. Comparison of observed performance of conventional cesium vapor diode with computed performance for reference converter (solid lines and circles). Observed performance of the Pt-Nb diode described in Section VI is also shown. 


\section{APPARATUS FOR EXPLORING CONVERTER INNOVATIONS}

\section{Vacuum Systems}

Because the experimental converter work is proceeding in two concurrent phases, two main systems of apparatus have been constructed. One of these, the demountable test vehicle, is a ceramic-metal ultra-highvacuum system capable of operating at high cesium pressures and fitted with flanges for repeated assembly and disassembly. This system is used for development and characterization of electrode surfaces, and for exploration of advanced modes of converter operation through "breadboard" testing of the associated electrode configurations. The other main system is a glass bell-jar vacuum system for testing permanently-sealed cylindrical converters to demonstrate advanced modes of converter operation under conditions approximating practical application. Fig. IV-I is a photograph of the two vacuum systems.

Demountable Test Vehicle

The working chamber for this system is a 4-inch diameter by 6-inch high stainless steel cylinder with a sapphire window on one side, closed on one end by a demountable copper-gasketed flange. As shown in Fig. IV-2, the chamber is evacuated through a I" $^{\prime \prime}$ all-metal high temperature valve by a combination titanium-sublimation getter-ion pump (UItek Boostivac Model 210-1500). In addition to a capability for high temperature bake-out of the system under ultra-high vacuum, this pump permits thorough elimination of all active impurities from any inert gas admitted to the working chamber through the titanium sublimation chamber.

A second small cesium-compatible valve connects the working chamber to the cesium supply. In the closed position, this valve acts as the cesium reservoir. It also allows the cesium to be trapped and isolated when the system is let up to air.

The demountable flange of the working chamber includes a rotatable base-plate insert on which are mounted all the internal parts of the test assembly and all the electrical feed-throughs. Various experimental configurations therefore are constructed on separate base-plates which can be inserted into the system for test at the appropriate time. A heating jacket allows the work chamber and base plate to be brought up to bake-out or cesium operation temperature.

Bell-Jar System

This system is mounted directly on the flange of a renovated $100 \mathrm{l} / \mathrm{sec}$ getter-ion pump, as shown in Fig. IV-3. The experimental assembly is mounted on an aluminum collar which contains all the vacuum feed-throughs. Above the collar, a 6-inch diameter pyrex glass tube forms the experimental chamber, which is closed at the top by an 
aluminum plate. The four major components (pump, collar, glass tube and top plate) are sealed with Viton O-rings and are held together by atmospheric pressure and gravity.

The bell-jar system is used both as a utility vacuum system and as a test bed for the cylindrical converters. The cylindrical converters are constructed as separate modules (see section $V$ of this report) and "plugged" into a heat-choke assembly mounted in this vacuum system for operation as shown in Fig. IV-3. Temperature control for the collector and cesium reservoir of these converters is provided by independent electrical heaters and a water-cooled heat sink. The emitter is heated by electron bombardment from a filament inserted into a cavity along its axis. A motion feed-through in the top plate of the bell jar allows the filament position to be readjusted during operation if necessary. Emitter temperatures are determined by an optical pyrometer through a window in the top plate.

\section{Pulse Generator}

A Velonex Model 360 pulse generator is used for studies of converter output enhancement by pulsed operation. 1,2 The direct output of this generator is matched to a $200 \mathrm{ohm}$ load, giving a pulse with a continuously variable amplitude up to $2.5 \mathrm{Kv}$ max., a rise time of about $0.02 \mu \mathrm{sec}$, a continuously variable pulse width from $0.05 \mu \mathrm{sec}$ to $3 \mathrm{msec}$, at a continuously variable pulse repetition rate from $1 \mathrm{hz}$ to $300 \mathrm{Khz}$ (with optional extemal triggering), consistent with a 31 Kwatt peak pulse power and 460 watt average continuous power. Various load-matching plug-in output transformers are available for peak pulse currents up to 750 amperes with other output limitations.

The plug-in transformer used in the present work (Model V-1197) can deliver pulses up to 400 amperes at 60 volts max. with pulse widths from 0.3 to $1 \mu \mathrm{sec}$, and minimum rise time of about $0.1 \mu \mathrm{sec}$. Considerable care must be taken in the low-impedance converter circuit to suppress unnecessary circuit inductance, e.g. through the use of stripline transmission line from the pulse generator to the converter, and to block spurious transmission of the pulse into the load and measurement instrumentation. Otherwise the rise time is greatly increased, and large undesirable transients (ringing, etc.) accompany the pulse. A wide-band current-measuring transformer and fast-rise oscilloscope are required for observing and accurately measuring the pulse shape.

In the work to date, the use of stripline outside the bell jar and conventional leads inside has permitted obtaining a rise time of about $0.1 \mu \mathrm{sec}$ and an otherwise acceptable pulse waveform. However, the poor coupling through the conventional leads causes a significant reduction in the amplitude of the pulse delivered to the converter and troublesome interaction with the thermocouple and other measurement circuits. In future work the low-loss, low-inductance transmission line will be extended into the bell jar to efficiently couple the generator to the converter electrodes. 
Pulse Enhancement Circuits

Fig. IV-4 shows the circuit used for applying and measuring pulses to a diode converter in the forward direction (negative potential pulse applied to emitter). The use of a sweep transformer as a load, as shown in this figure, makes it possible to sweep the complete IV characteristic at $60 \mathrm{hz}$ during pulsing, which speeds the acquisition and analysis of data (see Section $V$ or References $I$ and 2). However, the diode output decays at nearly constant current after each pulse because of the large inductance of the sweep transformer. In general a constantvoltage decay is preferred since it tends to hold the ions in the plasma and therefore significantly increases the decay time.1

Pulses in the reverse direction are applied and measured with the circuit shown in Fig. IV-5. In this figure a constant-voltage power supply is used as a load, which gives a constant-voltage decay after each pulse. This greatly slows and complicates data acquisition since only static or slowly swept operating points are possible, with the associated variations in electron cooling and emitter temperature.

\section{SECTION IV REFERENCES}

1) N.S. Rasor and E. J. Britt, Thermionic Conversion Specialist Conference. San Diego, California, (Oct., 1971) p. 272.

2) E. J. Britt and N. S. Rasor, Final Technical Report Contract NO0014-70-C-0252, NSR-1-4, (oct. 31, 1971 to June 30, 1972). 


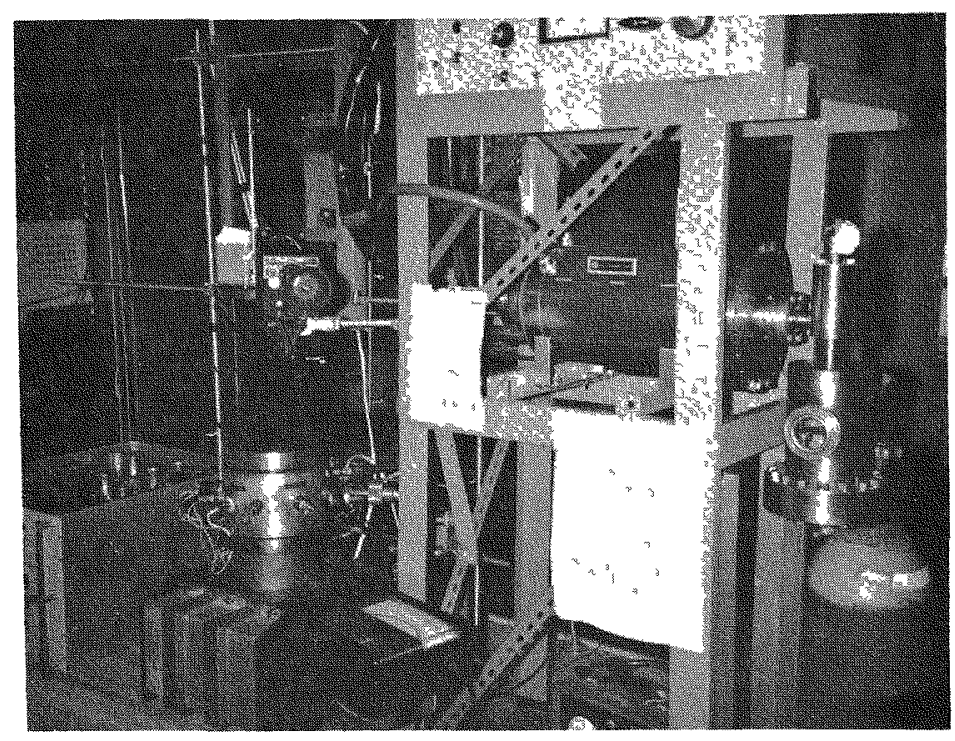

Fig. IV-1. Photograph of demountable test vehicle system (right) and bell-jar converter test system (left).

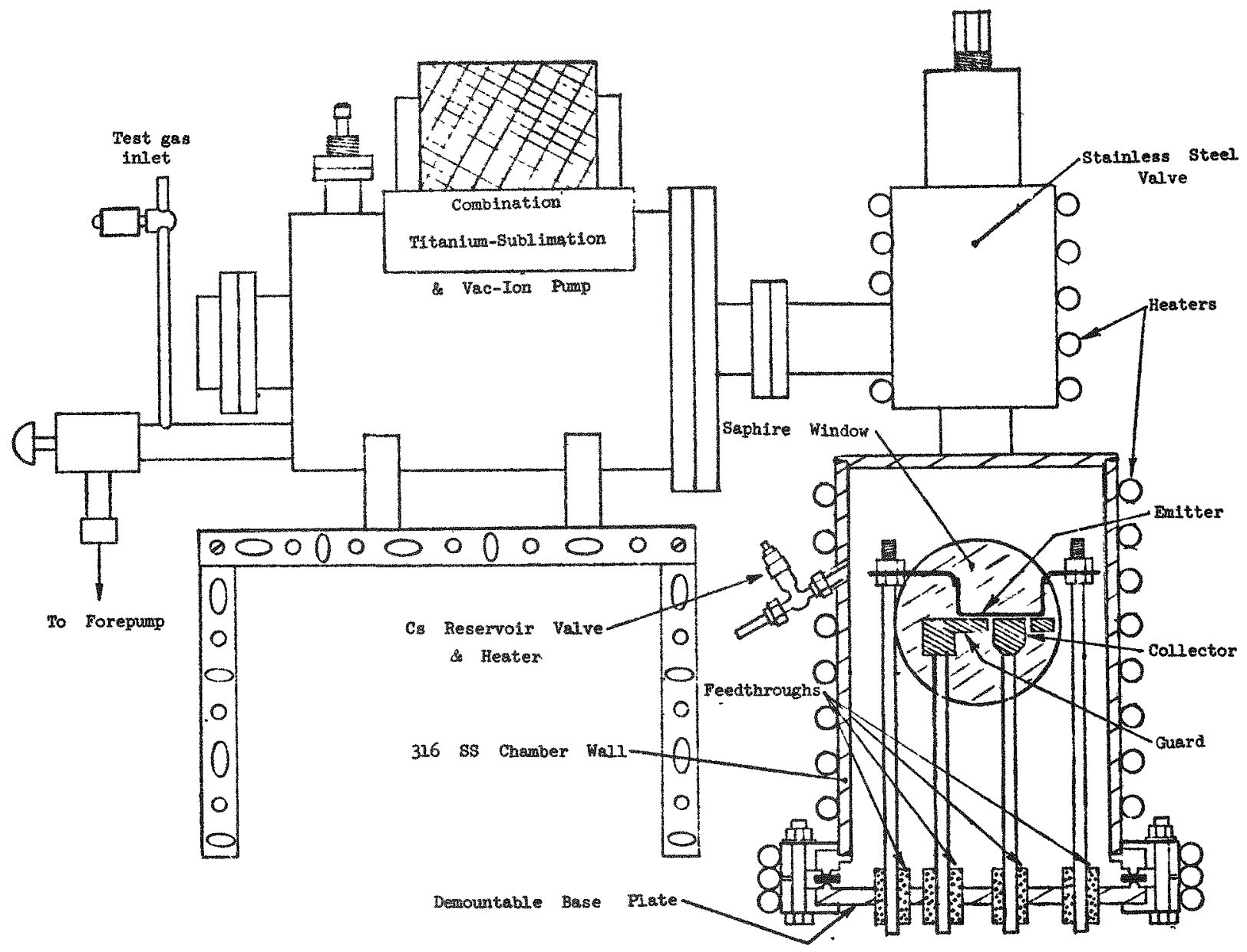

Fig. IV-2. Demountable test vehicle system layout. 


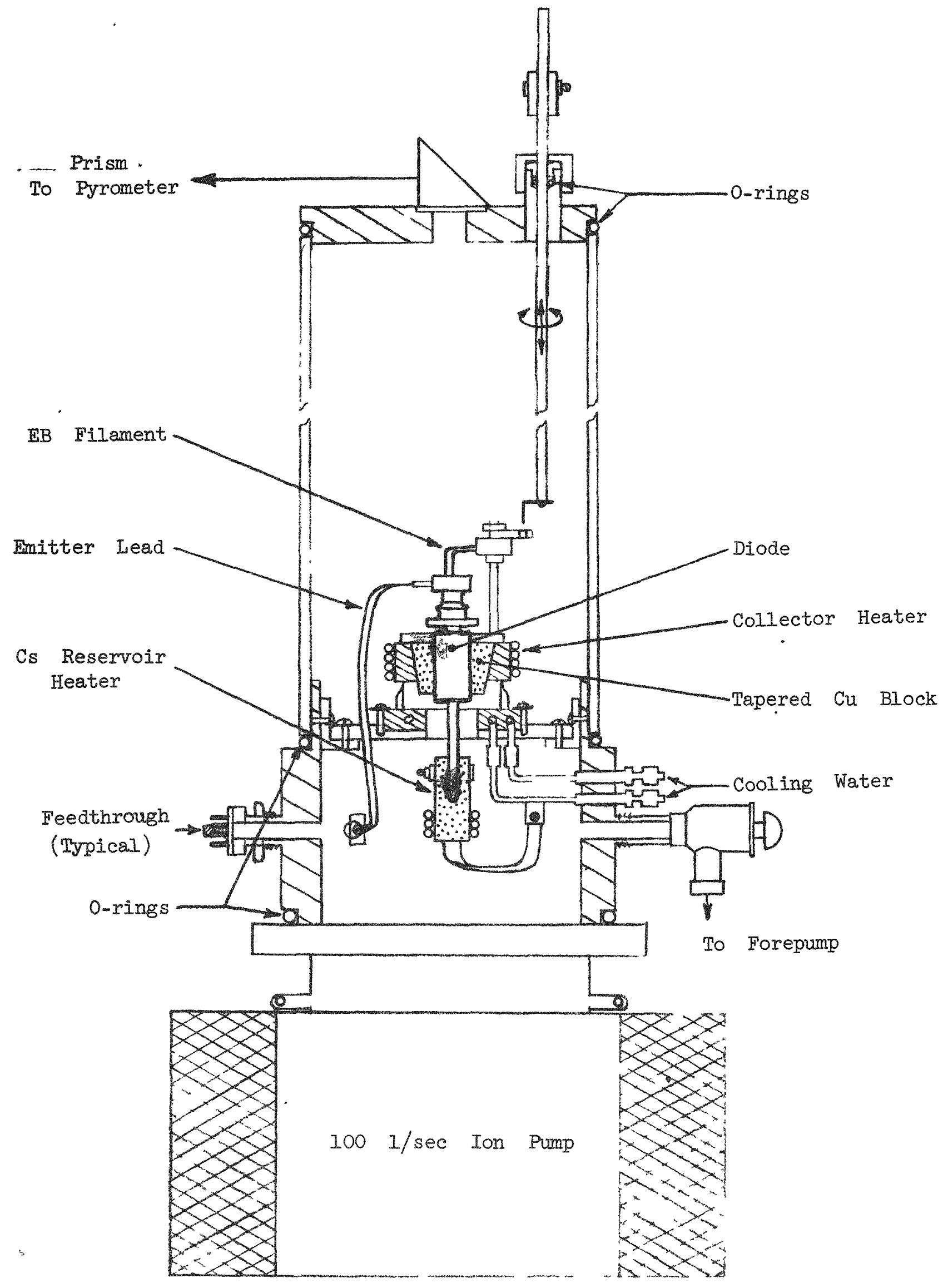

Fig. IV-3. Bell-jar converter test system layout. 


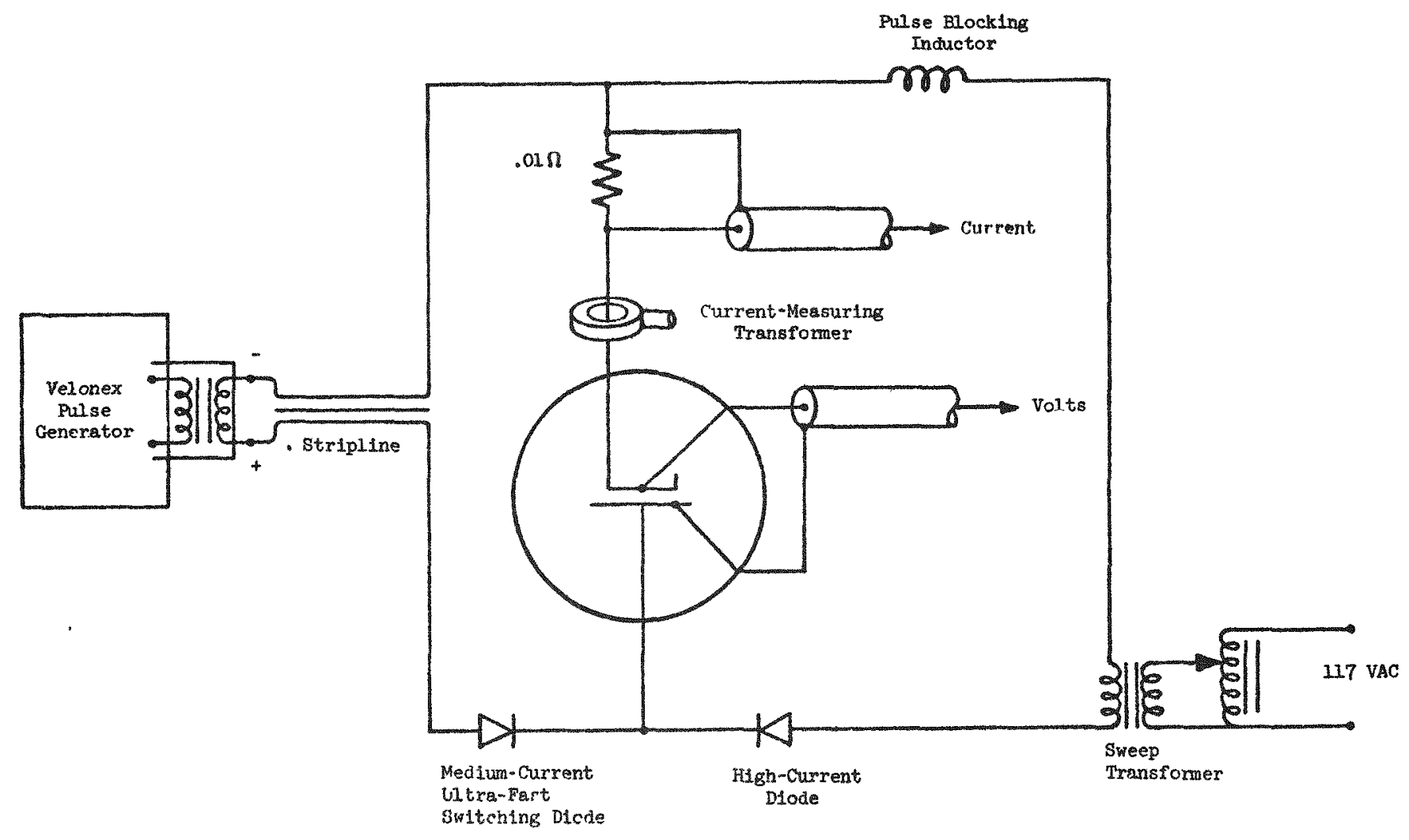

Fig. IV-4. Circuit for forward pulsing, with IV sweep and constantcurrent decay.

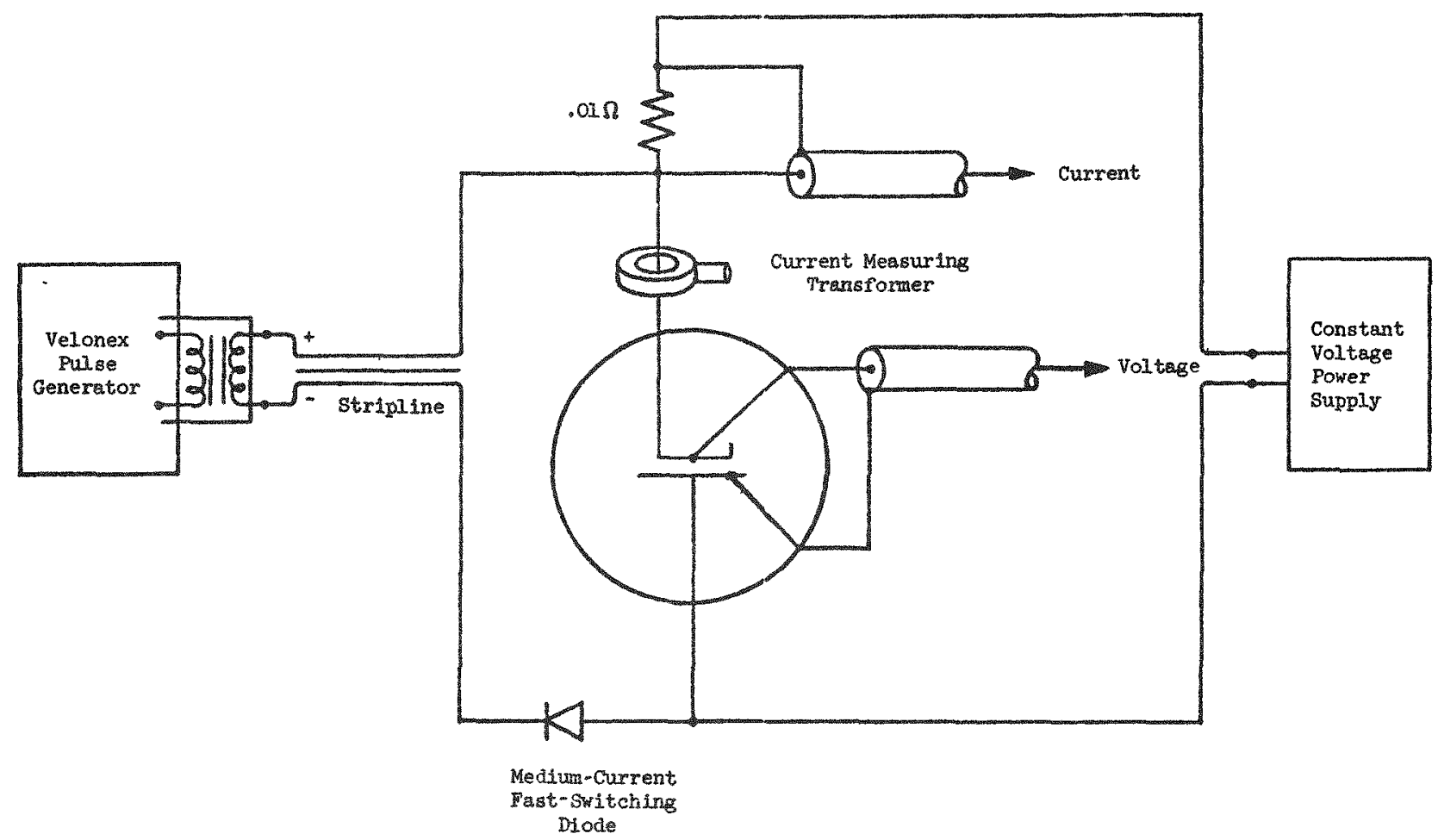

Fig. IV-5. Circuit for reverse pulsing, with static load and constant-voltage decay. 


\section{CVIINDRICAL DIODE WITH NIOBIUM EMITTER}

\section{Description of Converter}

The construction and operation of the type of converter used for this phase of the work is described in detail elsewhere. I Due to its elementary design ( 5 basic parts as shown in Figs. VI-1 and -2), it is relatively inexpensive and simple to modify and reproduce. It is assembled solely by elementary circular welds. Since a commercially available, copper-brazed ceramic-metal seal is used, no brazing operation is included in the assembly procedure. Previous experience with operation of a couple dozen of this type of converter has shown it to be highly efficient, reliable and easy to use for test purposes over a wide range of experimental variables. For these reasons, and because it approximates a practical configuration, this type of converter is highly suited for the demonstration phase of the present work.

As described previously, the program strategy is basic evaluation of advanced configurations and electrodes in the demountable test vehicle, and subsequent incorporation of the optimum design parameters and materials into a cylindrical test converter. Both the demountable and cylindrical systems were near completion at mid-year. However, the announced termination of the program suggested that there might not be sufficient time to complete both a basic exploration phase and a credible demonstration of optimum pulse-enhanced converter operation in the cylindrical configuration. It was decided, therefore, to proceed directly with the cylindrical converter configuration employing an emitter having the highest probability of providing the required emission properties, based on available data.

Platinum was chosen for, the emitter since its emission properties in cesium vapor had been measured up to $1800^{\circ} \mathrm{K}$ and, as shown in Section VII of this report, appeared to be adequate for optimum pulseenhanced operation of a Xe-Cs diode. Because. of the mechanical weakness of platinum at emitter temperatures, it was necessary to support the platinum emitter by a substrate electrode of a more refractory metal. Niobium was chosen for the substrate electrode, as shown in Fig. VI-I, since the thermal expansion of platinum and niobium are nearly the same.

In order to check out the experimental apparatus and obtain its baseline performance characteristics, this cylindrical converter was first placed in operation with only the substrate niobium electrode acting as the emitter. The configuration for these tests was the same as in Fig. VI-I, except that the platinum sleeve was omitted, and the spacing was smaller (amout 8 mils) in order to more closely approach the optimum spacing for a niobium emitter. This Section describes the experimental results obtained using the niobium emitter. 
Enitter Behavior

When first put into operation the No emitter showed unexpectedly high emission currents (low work functions) in cesium vapor. The emitter work function inferred from the transition point in the ignited mode is shown in Fig. VII-I. The effective bare work function $\phi_{0}$ for the initial data appears to be near $\phi_{0}=4.5 \mathrm{ev}$ at $10 \mathrm{w} \mathrm{T} / \mathrm{T}_{\mathrm{R}}$, and makes a transition to much higher values $(\approx 5.4 \mathrm{ev})$ at higher $\mathrm{T} / \mathrm{T}_{\mathrm{R}}$. This type of transition is imilar to the transition observed in cesium-oxygen data, which has been identified with the reversible dissociation of adsorbed molecular cesium oxide. 2 Later data, obtained after several excursions to higher temperatures $\left(\sim 1900^{\circ} \mathrm{K}\right)$, approached a fairly constant value of $\phi_{\mathrm{o}}=4.5 \mathrm{ev}$, as shown in Fig. TKI-1. This should be compared with the value of $\phi_{0}=4.2 \mathrm{ev}$ found to characterize Houston's data for clean niobium in cesium vapor.3 This behavior might arise from the fact that a significant amount of oxygen, which is highly soluble in niobium, was present initially in the emitter, was dispensed to its surface during initial operation, and was mostly exhausted from the emitter during the hightemperature cycles. Similar behavior was reported by Houston for tantalum, which strongly resembles niobium as a solid state oxygen getter.

An attempt was made to restore the initial enhanced emission state since, as indicated in Section VII, this performance would be adequate to meet the emitter requirements for optimum pulse-enhanced diode operation. The emitter was operated for extended periods at each of several temperatures while oxygen at a pressure of about $10^{-5}$ torr was maintained in the electron bombardment chamber of the emitter. It was hoped that this oxygen would be absorbed by the niobium and then be dispensed from its emitting surface in the diode. Unfortunately, this treatment did not restore the enhanced emission state. On another occasion, after the vacuum system had been cycled to atmospheric pressure, enhanced performance was not obtained initially. However, after a brief excursion to $1900^{\circ} \mathrm{K}$, the enhanced emission state was obtained for a short time at $1400^{\circ} \mathrm{K}$.

It seems, therefore, that an oxygen-dispensing niobium emitter might meet the requirements for an advanced mode of converter operation. It is clear, however, that the conditions for obtaining stable enhanced emission need to be systematically defined before it can be utilized practically.

\section{Pulsing Results}

In addition to evaluating the niobium diode in the conventional ignited mode, attempts were made to pulse-enhance this converter. The pulse generator was connected to the diode as shown in the schematic diagrams of Figs. IV-4 and 5. Both forward (same direction as emission current) and reverse current pulses were used. No combination of Cs pressures and temperatures was observed to produce a net power gain by either forward or reverse pulsing of the niobium diode. 
It should be pointed out that the conditions achievable in this niobium diode are far from optimum for pulse-enhancement as defined by previous basic analysis. 5 First, the cesium pressure required for adequate emission from the niobium emitter is much too high for efficient electron transport and ion generation. Second, since the ion transport time and therefore the plasma decay time between pulses are directly proportional to the spacing, the plasma decay time for this diode ( 8 mil spacing) is an order of magnitude smaller than that obtained in previous pulse-enhanced diodes investigated in this project $(\sim 100$ mil spacing). Third, the basic figure of merit5 for pulse enhancement in pure cesium vapor is distinctly inferior to that for xenon in which the previously favorable results were obtained.

The purpose of the tests with the niobium emitter was to verify that the observed ignited mode operation of this diode with a conventional emitter material and configuration is similar to that obtained in previous converters. Since the observed output characteristics were indeed consistent with previous data, this provided a baseline performance for credible identification of advancements achieved by innovations in this converter as evaluated in this apparatus. The inferior pulse. enhancement observed was essentially a confirmation of expectations for these tests, based on present understanding.

\section{SECTION V REFERENCES}

1) N. S. Rasor and C. C. Weeks, "Thermionic Converters for Compact Nuclear Power Plants", Atomics International Report NAA-SR-7144, Aug. 1962.

2) N.S. Rasor, Thermionic Conv. Specialist Conf., San Diego, Calif., (oct. 1971) p. 181.

3) N. Rasor and C. Warner, J. Appl. Phys. 35, 2589(1964).

4) J.M. Houston and P. K. Dederick, Thermionic Conv. Specialist Conf., Cleveland, Ohio, (Oct. 1964) p. 77.

5) N.S. Rasor and E. J. Britt, Thermionic Conv. Specialist Conf., San Diego, California, (oct. 1971) p. 272. 


\section{CYLINDRICAI DIODE WITH PIATINUM EMITTER}

\section{Design Considerations}

Following the preliminary tests performed with the niobium emitter, the cylindrical diode was disassembled for modifications. These modifications were to allow the optimum conditions for pulse enhancement to be approached for practical demonstration of this mode of operation in a cylindrical converter. They consisted of cladiing the niobium emitter with a platinum sleeve and increasing the spacing from $8 \mathrm{mils}$ to $50 \mathrm{mils}$. The increased spacing was necessary to obtain a sufficiently long plasma decay time. The platinum emitter was expected to emit several amp $/ \mathrm{cm}^{2}$ at cesium pressures ( $\sim 0.05$ torr) which give an electron mean-free-path about equal to the electrode spacing at $50 \mathrm{mils}$, i.e. the optimum condition for pulse enhancement indicated by previous analysis.I Fig. VI-I is a drawing of the diode with the platinum-clad niobium emitter and Fig. VI-2ais a photograph of its components.

\section{Diode Modifications}

A platinum sleeve .040 inch thick was prepared to clad the niobium emitter. An attempt was made to "shrink fit" the Pt sleeve over the niobium to insure a good thermal bond. This was done by heating the platinum and rapidly pressing it down over the niobium, which had been pre-chilled. This procedure failed at first because the soft platinum buckled under the stress of being forced on. After some difficulty, the sleeve was straightened and successfully installed over the niobium by using less interference in the fit. The sleeve was then mechanically swaged onto the niobium to obtain the required thermal contact. The adequacy of the thermal contact was verified by heating the emitter assembly with its electron bombardment filament while suspended freely in the high vacuum system. Local temperature non-uniformity was less than $\pm 5 \%$, and the axial temperature was uniform within $\pm 20 \%$.

\section{Platinum Emitter Performance}

The platinum diode was first operated as an ignited mode convertex to determine emission characteristics. The emitter performance observed was somewhat poorer than expected. Houston's data2 for platinum emission in cesium corresponds to a bare work function of $\phi_{0} \approx 6.0 \mathrm{ev}$. However, the emission from our platinum emitter, as determined from the transition point in the ignited mode, was characterized by $\phi_{O} \approx 5.5 \mathrm{ev}$ on a T/TR plot (see Fig. VII-I). The emission was slightly better than this immediately after start-up, but after a few hours of operation it approached and remained constant near $\phi_{\circ} \approx 5.5 \mathrm{ev}$. In fact, this value was unaffected even by ion bombarlment during reverse pulsing. This anomalous result is consldered further in Section VII. 


\section{Initial Ignited Mode Characteristics}

The initially observed electrical output characteristics of the diode with the Pt-clad emitter, Fig. VI-3, were generally in accord with expectations for conventional ignited mode operation. One exception is that the output voltage, after correction for the potential drop in the emitter stem (i.e. $16 \mathrm{mv} / \mathrm{amp} / \mathrm{cm}^{2}$ ), was about 0.1 volt less than expected. Collector emission measurements indicated that this discrepancy was not due to an unexpectedly high collector work function. A non-uniform emitter temperature or a temperature measurement error of about $60^{\circ} \mathrm{K}$ would account for this discrepancy, but errors of this magnitude seem unlikely based on the preliminary emitter temperature calibration mentioned above.

It is possible that the are drop in this converter was 0.1 volt greater than that in conventional converters because of the exceptionally large spacing used here in proportion to the emitter diameter and length. First, the collector area was $50 \%$ greater than emitter area, causing a much larger radial divergence in the plasma current flow than is present in conventional converters. Second, the area available for edge (end) Iosses from the plasma in this diode is proportionately much larger than in conventional cylindrical or guard-ring-planar converters. The second consideration could be especially important in view of the presence of an unusually strong ion-sink (high work function) at the exposed ends of the niobium substrate.

Pulse Enhancement Tests

Forward Pulses. Although the performance of the platinum enitter was significantly poorer than expected, it was sufficiently good that efficient pulse enhancement was expected to be obtained at low current densities, based on previous data and basic understanding. However, no enhancement at all could be obtained during forward pulsing of this diode (negative emitter pulses using circuit in Fig IV 4 ). We have no satisfactory explanation of this negative result which we also obtained during forward pulsing of a large close-spaced cylindrical cesium diode at Gulf General Atomic. 3 This behavior could result from a unique configurational aspect of these cylindrical diodes that might cause a forward puise to by-pass the interelectrode gap, e.g. via a discharge in the emitter stem region. This effect is not inherent to all cesium diode configurations since enhancement was obtained with pulses of either polarity in tests we performed on a planar cesium diode at Thermo Electron.3 This anomaly could be resolved by visual observation of the interior of the cylindrical diode during pulsing.

Reverse Pulses. Reverse pulses were applied using the circuit in Fig. IV-5 which aIso provides for constant voltage decay between pulses. Relatively efficient enhancement of the Pt-Nb cesium vapor diode was obtained initially using reverse pulses. For example, initially at $\mathrm{T}_{\mathrm{E}}=1490^{\circ} \mathrm{K}$ and $\mathrm{T}_{\mathrm{R}}=490^{\circ} \mathrm{K}$, the maximum power output in the ignited mode without pulsing was 0.73 watt $/ \mathrm{cm}^{2}$. During pulsed 
operation the maximum average power output was about 1.1 watt $/ \mathrm{cm}^{2}$ with an average pulse power input of about 0.1 watt $/ \mathrm{cm}^{2}$, or a net power output of about 1.0 watt $/ \mathrm{cm}^{2}$. Therefore, the required average pulse power input was observed to be about $30 \%$ of the total enhanced power increase, compared with a value of about $20 \%$ observed previously for a pulse-enhanced xenon diode. 4 This was in essential accord with previous theoretical estimates which indicated that the pulse power required to eliminate the arc drop in a cesium diode should be about twice that required in a xenon diode for the same output current.

Mapping of the pulse-enhanced operation of this diode was begun in order to obtain a more detailed comparison with the theoretical analysis. However, over a period of several days of operation the effectiveness of the pulses in enhancing the output progressively decreased until pulse-enhancement essentially disappeared for practical purposes. As the enhancement disappeared, the plasma decay times remained as long as they were initially ( $100 \mu \mathrm{sec}$ ), and pulse measurements indicated that the voltage and current of the pulses delivered into the diode were unchanged. Therefore it appeared that ions were still being generated in the diode, and that they were not being lost any more rapidly, but that the pulse-generated ions became less effective in enhancing the output current.

Attempts to recover efficient pulse-enhancement in a new operating regime were unsuccessful. At this time attention was turned to investigation of the surprising changes in the ignited mode which arose during this two-week period of operation.

Anomalous Ignited Mode Characteristics

Because the IV output characteristics were not swept dura" the foregoing constant-voltage operation, the significance of sulsiutial changes in the unpulsed ignited mode, which apparently accompanied. the loss of pulse enhancement, was not initially recognized. However, When the IV sweep of the characteristics was restored, it became apparent that the output voltage in the ignited mode had increased substantially. It appeared that the are drop had in fact disappeared. of course, this would explain the observed inability to suppress the are drop by pulsing if there were indeed no arc drop to suppress. Yet it was very difficult to accept such a result since it was entirely unexplainable and without apparent primary cause.

Comparison of the output characteristics in Fig. VI 4 , taken at that time, with the initial characteristics show in Fig. VI-3 shows that the envelope of the family of curves has been increased by $0.5-0.6$ volt, and the apparent saturation currents about halved. The increase in output voltage could have arisen from an erroneously high emitter temperature, a decrease in the collector work function, or a decrease in the arc drop. Both the correlation of emitter temperature to the voltage in the obstructed region of the ignited mode 6 and to the open circuit voltage 5 would require an error in emitter temperature measurement of about $150-200^{\circ} \mathrm{K}$ to explain the 
increase in output voltage. However, diagnostic checks of the pyrometric system, and repetition of emitter transient cooling tests, revealed no change in the measurement conditions between Figs. IV-3 and IV-5 which could account for an error of this magnitude. Also the collector work function inferred from collector back emission measurements remained constant near $\phi_{C}=1.43$ ev throughout the period of change, as did the optimum collector temperature $\left(\sim 870^{\circ} \mathrm{K}\right)$.

The only consistent assumption therefore appears to be that the arc drop decreased essentially to zero during this period of change. Perhaps the most convincing evidence of this is the substantial increase in overall energy conversion efficiency which accompanied this change. Although careful calorimetric measurements were not made, the total electrical power input to the emitter bombardment heater remained about constant, even though the total electrical power output of the converter increased substantially during this period. In fact the overall energy conversion efficiency corresponding to the conditions in Fig. IV-5 at $1400^{\circ} \mathrm{K}$ emitter temperature, $i . e$. the ratio of the total electric power output (into a static load) to the total electric power input to the emitter heater, was in the vicinity of 10-12\% at an output power density of about $2 \frac{1}{2} \mathrm{w} / \mathrm{cm}^{2}$. At $1500^{\circ} \mathrm{K}$ the overall efficiency was observed to be in the vicinity of $16 \mathrm{~m} 19 \%$ at $4 \mathrm{w} / \mathrm{cm}^{2}$. Reference to section III of this report will show that this approximates the performance expected for zero arc drop (i.e. 2nd Generation Performance at $\phi_{C}{ }^{\prime}=1.5 \mathrm{ev}$ ), especially considering non-idealities such as off-optimum emitter lead drop and emitter temperature non-uniformity in this device. In particular it should be noted that efficiencies substantially greater than $15 \%$ should not be obtainable under Ist Generation conditions ( $\left.\phi_{\mathrm{C}} \approx 2.0 \mathrm{ev}\right)$ for any achievable emitter temperature in this device (melting point of platinum is $2050^{\circ} \mathrm{K}$ ).

\section{Post Mortem Inspection and Discussion}

After several days of operation, during which the diode's performance showed continuous improvement, a short circuit occurred between the emitter and collector. When the diode was disassembled it was found that the platinum sleeve had moved axially downward along the niobium emitter by about .060 inch where it contacted the bottom of the collector. Although the reason for this movement is unknown, it seems likely that it occurred because of thermal ratcheting resulting from the silight mismatch in expansion coefficients of platinum and niobium. No other aspects of the diode interior showed any significant changes. Fig. VI-2b shows the final configuration of the emitter in the diode.

It seems likely, therefore, that the primary cause of the output, changes observed just prior to the short circuit was the change in the configuration of the emitter. A quantitative review of the possjhle changes in emitter temperature due to the movement or changes in the thermal bonding of the platinum sleeve indicates that such effects would be inconsistent with or insufficient to cause the observed change in output characteristics. The remaining inference therefore is that the change 
in the emitter configuration somehow modified the discharge in a manner which eliminated the arc drop. Although the basis for speculation is quite tenuous at present, a tentative mechanism for such behavior has been postulated which seems qualitatively reasonable.

As the cladding moved downward it formed a cylindrical cavity at the lower end of the emitter, as shown in Fig. VI-6. The inner cylinarical edge of this cavity was platinum, the upper flat end was niobium in contact with the platinum, and the lower flat end was the collector surface. In the final stages when high performance was obtained, this cavity communicated with the main interelectrode space only through a narrow gap between the lower edge of the platinum sleeve and the bottom of the collector. As shown in Fig. VII-I, the contact potential difference between platinum and niobium surfaces at the same temperature in cesium vapor is at least 0.6 ev (from our emission data in the present diode) or as much as $1.0 \mathrm{ev}$ (from Houston's data). Accordingly, when the potential drop between the platinum portion of the emitter and the collector is zero, the potential arop between the niobium portion of the emitter and the collector is $0.6-1.0$ volt. This is much more than the $0.4-0.5$ volt arc drop required to maintain an ignited cesium discharge across the cavity between the niobium bottom of the emitter and the adjacent collector.

A seemingly reasonable postulate therefore is that the convecter in this configuration was operating as an "ignited triode". "According to this postulate, excess positive ions generated in the high-potential ignited cavity discharge are swept into the low-potential regioc in the main interelectrode gap to neutralize and thereby maintain tho main interelectrode discharge with zero are drop. This two-sesion type of discharge in a triode ("plasmatron") configuration, using an auxilliary power supply to operate a third electrode, is well known.7 Its occurrence in a two-terminal device has not been reported or postulated previously within our knowledge. Since such a hybrid-mode diode converter would be much simpler to construct and operate in practical applications than a three-terminal triode or a pulsed diode, this concept deserves futher investigation.

Theoretical investigation of this mode of operation is in progress. A cavity-type region, with limited access to the main interelectrode gap, appears to be essential for existence of this mode of discharge. The cavity must have a large enough volume for total ion production, with the arc drop avallable, to exceed total losses. The rate at which Ions are drained from the ignited region must not be too great or it will de-ignite. This requires restricting the degree of communication between the cavity and the main interelectrode gap to only that required for neutralization of the main discharge current.

An additional important consideration is that ion-containing sheaths, such as those which can exist between the platinum and collr tror surfaces and the plasma, must be present at all surfaces adjacent to the path along which ions are transported to the main discharge. A quantitative relationship anong these several design considerations is being wought analytically. 
It is also planned to experimentally evaluate these factors by reassembling and retesting this diode with its present emitter (cavity) configuration, and by exploring altemate but equivalent configurations in the demountable test vehicle.

\section{SECTION VI REFERENCES}

1. N. S. Rasor and E. J. Britt, Summary Technical Report on Contract N00014-70-C-0252, NSR-1-3, (Sept. 1, 1970 - Oct. 31, 1971) p. III-1I.

2. J. Houston and D. Dederick, Thermionic Conv. Specialist Conf., San Diego, California (1965) p. 59.

3. N. S. Rasor and E. J. Britt, Thermionic Conv. Specialist Conf., San Diego, California, (Oct., 1971) p. 272. Also appears as Section IV in Reference 1.

4. N. S. Rasor and E. J. Britt, Final Technical Repor z cu Cont wCt No0014-70-C-0252, NSR-1-4 (Oct. 31, 1971 - June 30, 1372)

Sections IV and $V$.

5. Reference 4, Section VIII.

6. Reference 1, Section V.

7. N. S. Rasor, Third International Conf, on Themionic Elect. Power - Generation, Julich, Germany, (June, 1972), Vol. 3, pp. 1037-1038. Also appears in Reference 4 as Section IX, pp. 11-i2.

8. The definition of and condition for excess ion generation, i.e. $\left(\mathrm{Vd}>\mathrm{V}_{\mathrm{d}}^{\prime}\right)$, are described in Summary Technical Report on Contract No0014-C-0252, NSR-1-2, (Mar., 1970 to Aug., 1970), p. III-4. 


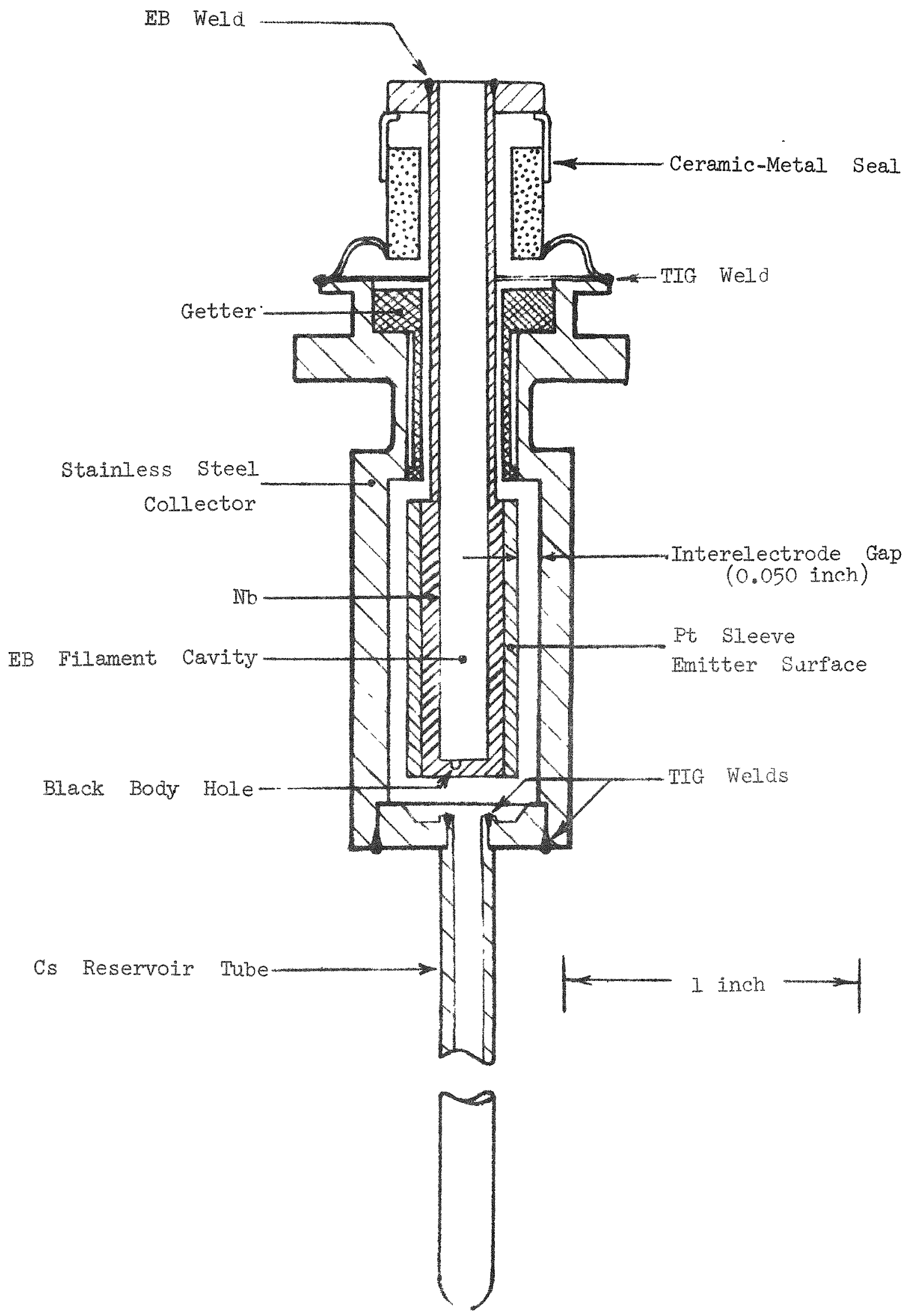

Fig. VI-1. Sketch of cylindrical converter with platinum-clad niobium emitter. 

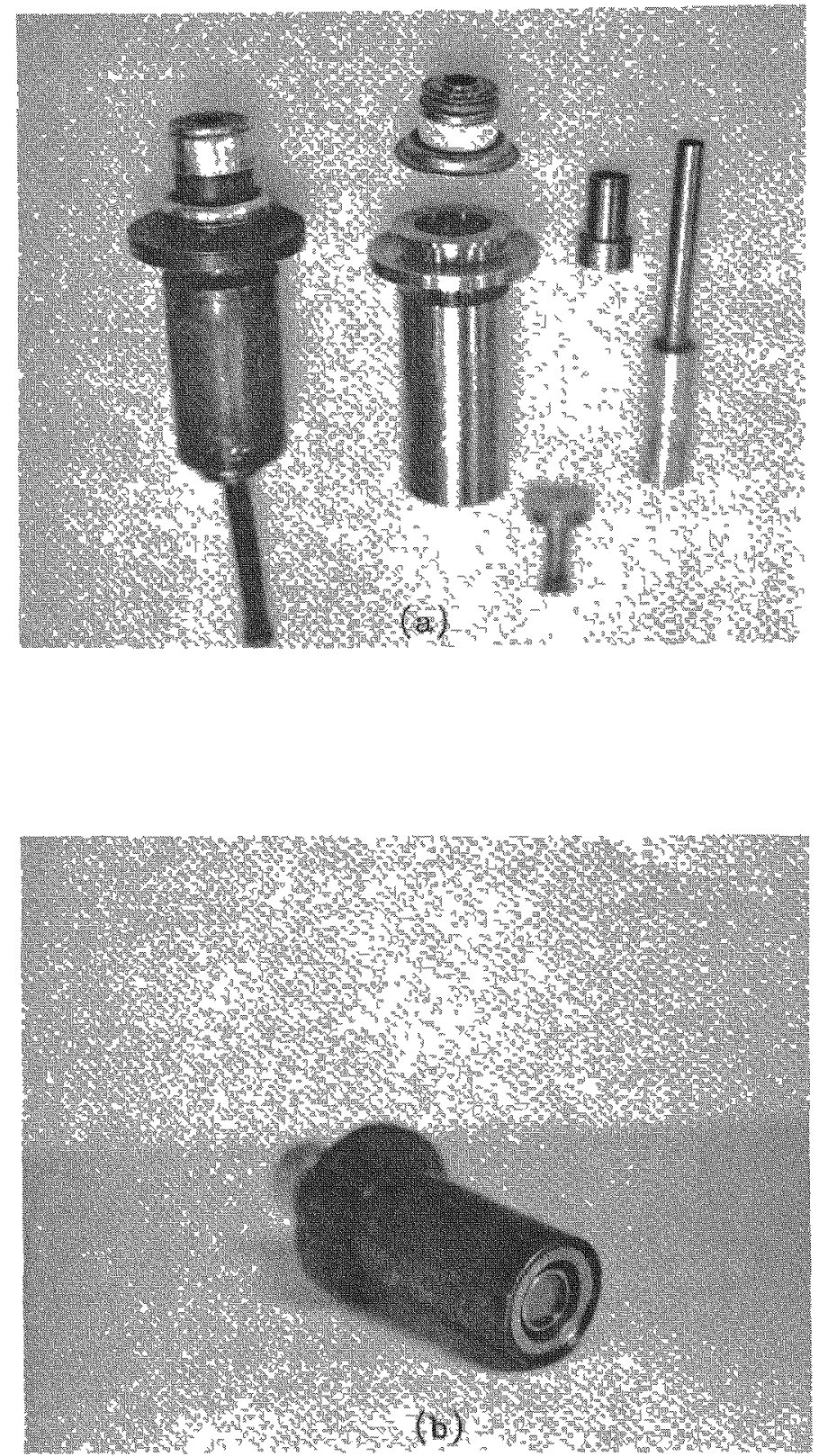

Fig. VI-2 (a) Photograph of assembled and disassembled cylindrical converter.

(b) Photograph showing cylindrical cavity formed at bottom of emitter by axial movement of platinum cladding. 

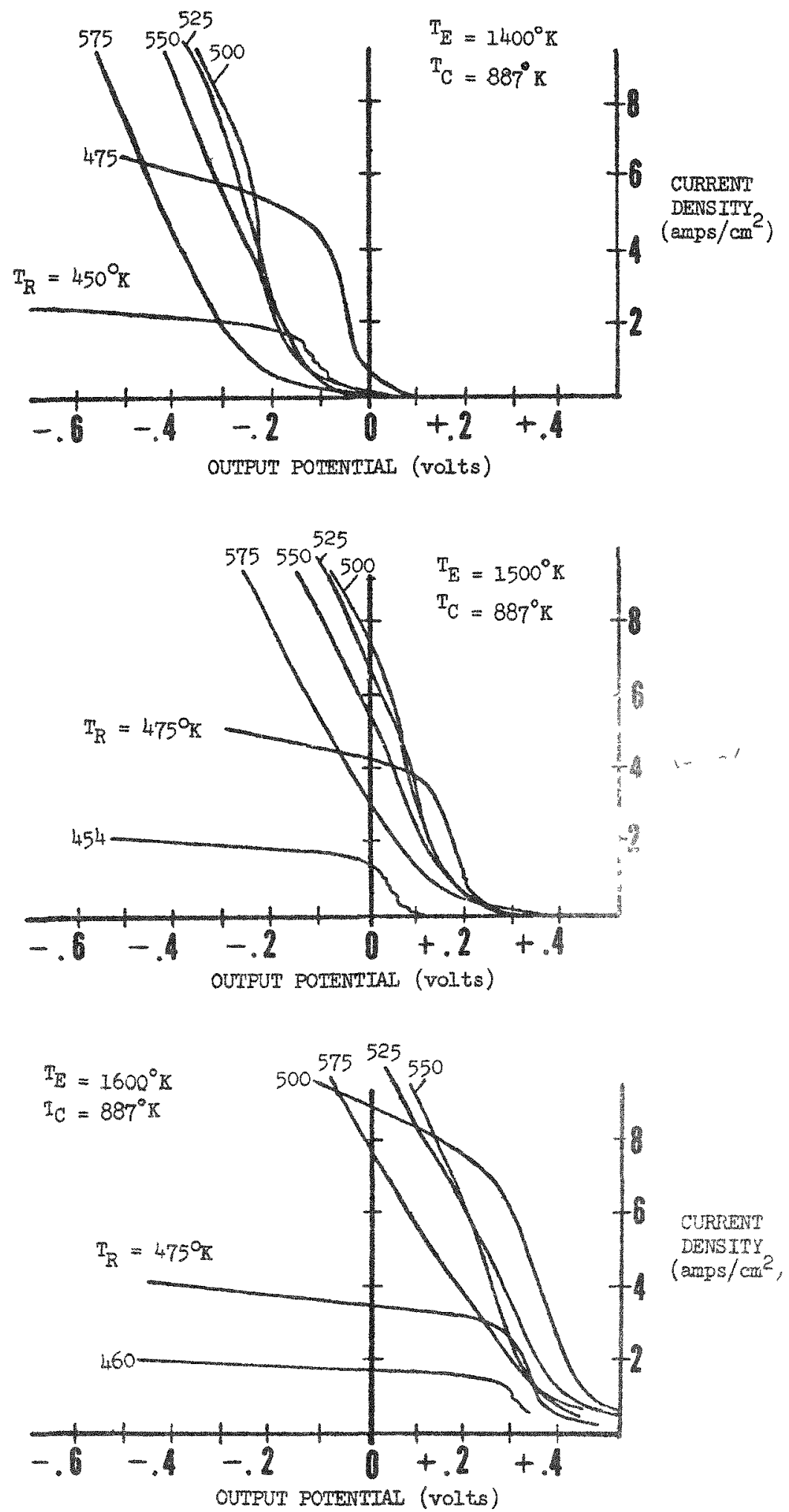

Fig. VI-3. Initial electrical output characteristics of Pt-Nb cylindrical diode. 

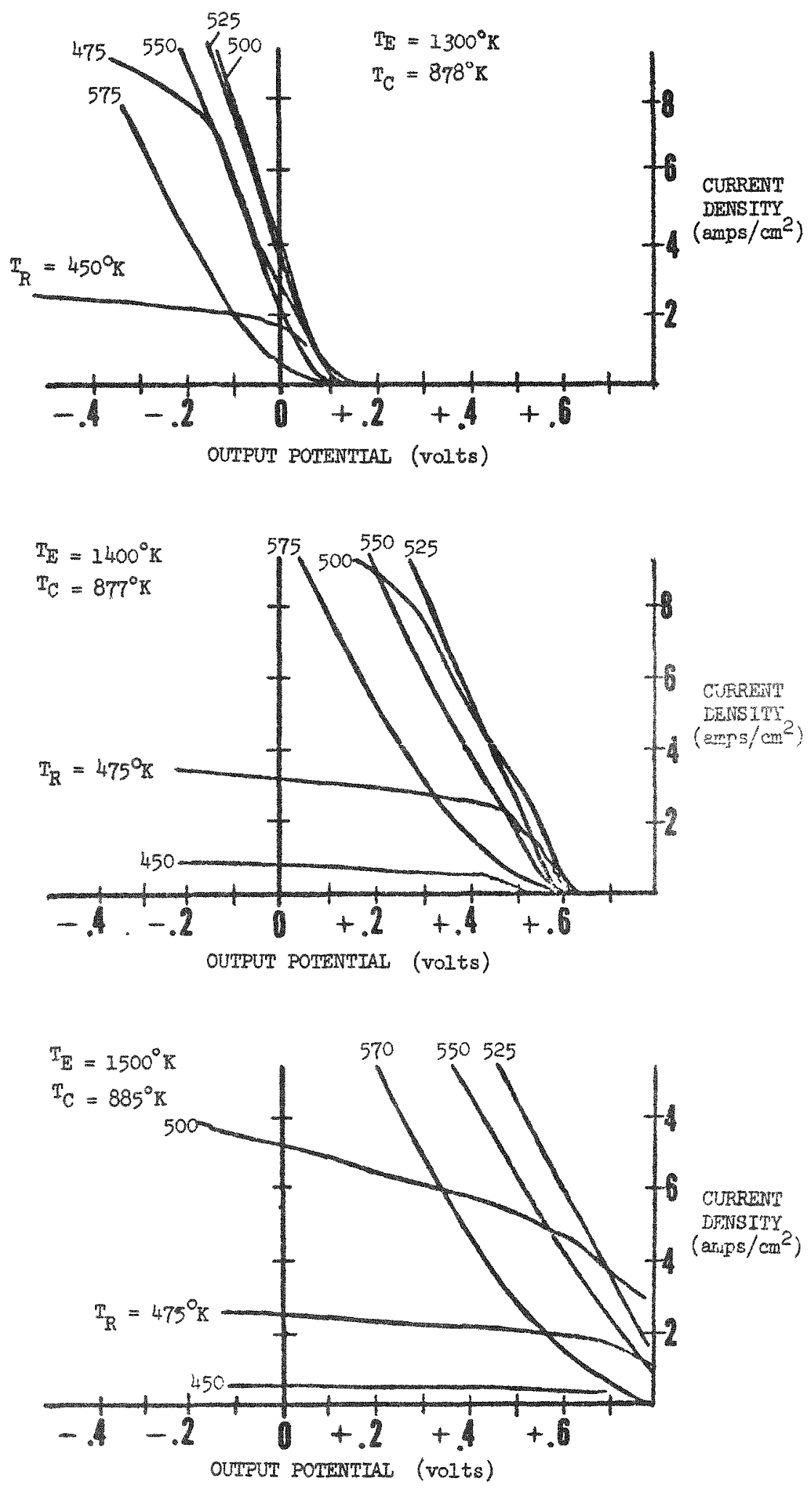

Fig. VI-4. Final (anomalous) electrical output characteristics of Pt-Mo cylindrical diode. 
VII. ELECTRODE TECHNOLOGY

Emitter Requirements for Advanced Converter Operation

An immediate target for advanced converter development is efficient and economic operation in a temperature region achievable with commonly used materials, e.g. the better stainless steels, Inconel, Hastalloy, etc. The upper temperature limit for such materials is presently between 1650 and $2000^{\circ} \mathrm{F}$ ( 1180 and $1360^{\circ} \mathrm{K}$ ). To obtain the necessary emission currents of 1 to $10 \mathrm{amp} / \mathrm{cm}^{2}$ at these temperatures, emitter work functions of about $1.9-2.1$ ev are required.

A feature common to essentially all converter operation modes in which the arc drop is suppressed is the requirement that the electron mean free path be of the same order or less than the interelectrode spacing $d$. This means that the cesium pressure $p$ must be sufficiently low that pd $\leqslant 3$ torr-mil. Economic construction of large area converters tends to require spacings of $d z 20 \mathrm{mils}$, and sufficiently long plasma decay times are obtained for efficient pulse-enhanced operation for $d \gtrsim 100 \mathrm{mils}$. These considerations therefore require emitters which give adequate emission at cesium pressures in or lower than the region 0.15 to 0.03 torr, corresponding to reservoir temperatures of $450<\mathrm{T}_{R}<4900 \mathrm{~K}$. Together with the above-described emitter temperature requirements, this defines the region of most immediate interest for emitters in advanced converters, shown as the shaded region in Fig. VII-I. The left and right boundaries of this region correspond to mean free paths of 20 and $100 \mathrm{mils}$ respectively, and the lower and upper boundaries correspond to emitter temperatures of 1180 and $1360 \mathrm{~K}$ ( 1650 and $2000^{\circ} \mathrm{F}$ ) respectively. It can be seen that the best conventional converter emitters (e.g. oriented tungsten or rhenium), which are characterized by $\phi_{0} \approx 4.8 \mathrm{ev}$, meet these requirements only marginally and at relatively close spacings and low temperatures.

It is generally desirable to exceed these requirements, if possible, since this permits operation with an ion-conserving sheath at the emitter. This also provides a margin of safety for maintaining adequate and unim form emission over a long lifetime. Therefore, the region immediately below and to the right of the region defined in Fig. VII-I is especially preferred.

\section{Advanced Emitters}

Known types of surfaces which could reach or exceed the advanced emitter requirements fall in the following categories and are discussed in that order:

1. Metals with an adsorbed electronegative layex (e.g. oxygen atoms) in pure cesium vapor.

2. Elemental metals in pure cesium vapor. 


\section{Metals in cesium vapor with electronegative elements dispensed to their surface.}

4. Metals with electropositive elements dispensed to their surface.

Fig. VII-1 shows the behavior of specific examples of such surfaces.

Type 1. The best reported emitter by far is that prepared by Langmuir ${ }^{1}$ which reportedly consists of a monolayer of atomic oxygen on tungsten. It is formed by exposing tungsten at $2000^{\circ} \mathrm{K}$ to oxygen at a pressure of 100 microns, and subsequently heating it to $1600-1800 \% \mathrm{~K}$ for a few seconds in pure cesium vapor at room temperature $\left(\mathrm{T}_{\mathrm{R}} \simeq 300^{\circ} \mathrm{K}\right)$. Langmuir used this surface in several different adsorption studies, and his data indicate that the half-life of the atomic oxygen layer at $1400 \mathrm{~K}$ should be over 100 years. Fig. VII-I also shows the behavior we observed ${ }^{2}$ for a surface prepared according to the Langmuir prescription. Although our emitter required significantly higher cesium pressures to reach the work functions of interest than did the reported Langmuir emitter, our emitter still greatly exceeded the minimum advanced converter requirements as defined above. The basic reason for the departure from the Langmuir results is not yet known. The principal question for practical purposes, i.e. the long-term stability of this surface as a converter emitter, also remains unanswered at this time.

Type 2. Data by Houston 3 for platinum in cesium vapor is included in Fig. VII-1. Although platinum is far superior to all other elemental metals as an emitter in cesium vapor, Houston's results indicate that some other members of the platinum family of metals also meet or exceed the performance required for advanced converters; i.e. rhodium, iridium and osmium all are characterized by $\phi \propto 5.5 \mathrm{ev}$ in the region of interest. A striking occurrence is that Houston's data for platinum and our data for atomic oxygen on tungsten are nearly identical over a wide range of values. If this is more than coincidence, it suggests that the unique properties of platinum arise from an adsorbed layer of oxygen which even Houston's repeated flashes to $1825^{\circ} \mathrm{K}$ did not remove. Fig. VII also shows the work functions inferred from the current in the ignited mode of our diode with the platinum-clad emitter (see Section VI). It can be seen that the performance of our platinum emitter was somewhat inferior to the results of Houston for platinum. Nevertheless, our platinum emitter met or exceeded the advanced performance requirement. The basic reason for the difference between our results and Houston's for platinum is not yet known. However, we could not flash our emitter to $1825^{\circ} \mathrm{K}$ before each measurement as did Houston, and our platinum emitter was mounted on a niobium substrate. It is possible that due to one or both of these differences a unique contaminant could have existed on our emitter surface.

Type 3. The envelope of work functions observed by French workers 4 for tungsten in equilibrium with various partial pressures of oxygen is included in Fig. VII-I. It is believed that the behavior in the higher work function region (Iying between $\phi_{0}=4.5 \mathrm{ev}$ and the envelope $\mathrm{A}-\mathrm{A}^{\prime}$ ) arises from the comadsorption of cesium and oxygen atoms, and cesium 
oxide and oxygen molecules, as discussed in the final part of this Section. Presumably this region also includes values potentially achievable by oxygen dispensed from an oxide layer on the collector, as demonstrated by Lieb and Rufeh 5 at Thermo Electron. It can be seen that this type of emitter can meet or exceed the advanced performance requirements. Compared to Types 1 and 2, this type may have a greater inherent stability and lifetime in practical use. However, the oxygen dispenser (e.g. a special collector surface) may impose undesirable constraints on the converter operating point for efficient operation of this type of emitter.

An alternative mode of operation of this type of emitter, with a different set of constraints, is to dispense oxygen to its surface by diffusion from the electrode interior. The oxygen can originate from decomposition of a compound impregnated into a porous emitter, from an oxygen chamber behind a porous emitter, or from oxygen in solution in a solid metal electrode. Enhanced emission due to oxygen dissolved. in tantalum has been reported by Houston, and we have observed similar behavior with a niobium emitter which presumably also was due to dissolved oxygen. Data for this oxygen-contaminated niobium emitter is included as the solid triangles in Fig. VII-I, and is discussed in Section $V$.

Type 4. Surfaces with an adsorbed Iayer of barium or strontium, maintained in equilibrium with their vapor or dispensed from an internal source, are known to give practically useful electron emission at the temperatures and long electron free paths required for emitters in advanced thermionic converters. This type of emitter therefore is worth consideration for this purpose, but only if a low-work-function collector is developed which is compatible with the evaporation products from these emitters.

\section{Advanced Collectors}

The distinctive region $B-B^{\prime}$ also occurs in the French tungstenoxygen data. Such behavior is quantitatively and qualitatively similar to that exhibited by the well-known cesium-silver oxide photo-cathode6. This surface is understood to be a cesium-doped bulk silver oxide semiconductor, suggesting that the region $B-B^{\prime}$ results from the existence of a cesium-doped layer of tungsten oxide with similar properties. This implies that collector work functions of 1 ev or less might be available with this type of surface, but possibly only at the relatively low electrode temperatures and cesium reservoir temperatures associated with the French deta $\left(T_{R}=315-3500 \mathrm{~K}\right)$.

Hybrid Mode Emitter

Included in Fig. VII-I are Houston's results for the work function of niobium in cesium vapor and values inferred from the ignited mode current in our cesium vapor diode with a niobium emitter (see Section V). 
After an extended operating period (open triangles), our niobium emitter was characterized by $\phi \simeq 4.5 \mathrm{ev}$, compared with the $\phi_{0} \simeq 4.3 \mathrm{ev}$ which characterized Houston's niobium. The basic reason for this difference is not known with certainty, but presumably arises because Houston repeatedly flashed his niobium at high temperatures prior to each measurement to remove impurities. Such impurities could have affected our results since such flashes were not possible in our experiment. In fact, according to the analysis described in the remainder of this Section, the observed behavior suggests the presence of a sufficiently high concentration of oxygen on the surface of our niobium that it exists as a layer of adsorbed cesium oxide molecules.

The principal purpose for including the niobium data in Fig. VII-I is to show that, for a given value of $T / T_{R}$, the contact potential (work function difference) between platinum and niobium is as much as 1 volt according to Houston's results, and as much as 0.6 volt according to our data. An emitter with separate regions of platinum and niobium therefore can provide sufficient arc drop to maintain a low-current ignited discharge to the collector in the niobium region, with a highcurrent discharge at zero arc drop in the platinum region.

\section{Basic Description of Cesium and Oxygen Co-adsorption on Tungsten}

A physical model and preliminary gnalysis for the Cs-O-W adsorption system have been described previously. ${ }^{8}$ Comparison of the initial results of this analysis with early experimental measurements indicated that the model is in essential accord with the gross phenomenology observed. Because of the growing practical significance of this type of emitter, and because of improved detail in more recent experimental data, further work has been performed toward achieving a more general and rigorous analytical formulation. This improved description should give better insight into the dominant physical processes, help guide their optimization for future practical use and permit sensitive diagnosis and quantitative characterization of changes which occur during long-term operation of practical devices.

The present state of the formulation will only be outlined here. Its full description will be included in a subsequent report along with detailed comparison of its results with available experimental data. Because of the number and complexity of simultaneous equations and our limited resources for data processing, it has not yet been possible to obtain detailed parametric plots of the results with which to make such comparisons. However, the expected availability of a programmable calculator should allow this to be accomplished.

In the physical model postulated, cesium and oxygen atoms and associated molecules of oxygen, cesium oxide and tungsten oxide are coadsorbed on the surface of tungsten. Equations defining their adsorbed state are obtained as follows:

1. For each dissociation reaction, statistical thermodynamics and the Langmuir surface phase postulate permit an equation to be 
written relating the equilibrium evaporation (departure) rates of the various species, in terms of the surface temperature, the atomic and molecular masses, and the molecular dissociation energies in the gas phase.

2. The requirement that at steady state the arrival rates of cesium and oxygen atoms (as either free atoms or in molecular form) must equal their departure rates yields a set of equations involving their partial pressures in the gas phase.

3. By again employing the Langmuir surface phase postulate and statistical thermodynamics, an equation for the evaporation rate of each species can be written in terms of its density on the surface, its adsorption energy, the frequency of oscillation in its adsorption site, and the surface temperature.

Taken together, these three sets of equations allow computation of the degree of surface coverage by each species in terms of their masses, dissociation energies and partial pressures in the gas phase, adsorption energies, oscillation frequencies and the surface temperature. This aspect of the computation is largely thermodynamic by nature and therefore is largely independent of detailed assumptions concerning the configuration and mechanics of the adsorption and dissociation processes.

The remainder of the formulation deals with estimation of the adsorption energies and the effect of each of the species on the work function of the surface. A rigorous treatment would proceed via a quantum mechanical analysis of a detailed physical model for each adsorbed species and its adsorption site. This is a formidable problem which would require simplifying assumptions and approximations to obtain tractable solutions, the validity of which must be tested by experimental data. Instead, a phenomenological approach is taken here. The simplify= ing assumptions and approximations are made immediately in the physical model of the adsorption process, rather than in the subsequent analysis, and the model is then adjusted to give satisfactory agreement with the best experimental data available. This approach is highly useful for practical purposes since it rapidly accommodates to changes in boundary conditions and application, and affords strong intuitive contact between basic cause and effect in observed data. This usefulness is obtained at the expense of rigor, analytical elegance and generality, however. The following assumptions and approximations are employed here:

1. It is assumed that the dissociated oxygen atoms and molecules interact with the cesium atoms only through their effect on the work function $\phi_{o \text { o }}$ of the surface in the absence of cesium; $i . e$. that the adsorption energies for oxygen and that $\phi_{\mathrm{og}}$ are independent of cesium coverage. Similarly, it is assumed that the adsorption energy for cesium is uniquely determined by the value of $\phi_{o O}$ via the Rasor-Warner formulation 9 for cesium in the absence of oxygen. 
2. The work function of the surface is then the algebraic sum of $\phi_{00}$ and the potential drop obtained by summing the dipole moments of the partial coverage of all other adsorbed species (except dissociated oxygen), proceeding as in the Rasor-Warner formulation.

The first assumption is justified by the fact that, due to its relatively small size and high adsorption energy, oxygen is adsorbed deep in the interstices of the surface and is immobile at these temperatures. The adsorption and dissociation energies of the adsorbed species, and the work function $\phi_{o O}$ of tungsten as a function of oxygen pressure, 10 have been determined by independent experimental measurements. The dipole moments (and polarizabilities) of the various adsorbed species can be estimated from independent experimental data but, in the final analysis, values should be chosen which give the best agreement with the available experimental $\mathrm{Cs}-\mathrm{O}-\mathrm{W}$ data. Oscillation frequencies and adsorption site densities can be estimated adequately from theory since the results are relatively insensitive to the values used.

Fig. VII-2 is a representative plot showing, in schematic form for illustration, the dominant features of observed data and their corresponding interpretation according to the formalism described. The validity of this interpretation and the relative significance of the basic processes in various regions of operation will be established after parametric mapping of the equations described.

\section{SECTION VII REFERENCES}

1. I. Langmuir and D. S. Villars, J. Am. Chem. Soc. 53, 486 (1931); and I. Langmuir, Industrial and Engineering Chemistry 22,390 (1930).

2. E. J. Britt and N. S. Rasor, Final Technical Report on Contract NOOOI 4-70-C-0252, NSR-I-4 (Oct. '7I to June '72), Section VII.

3. J.M. Houston and P. K. Dederick, Rept. of Thermionic Conv. Specialist Conf., San Diego, Calif. (Oct. 1965), P. 249.

4. T. Alleau and M. Bacal, Rept. of Thermionic Conv. Specialist Conf., Miami, Fla. (Oct. 1970), and J.I. Denisot, C.E.N. Saclay, private communication, Aug. 1972.

5. D. Lieb and F. Rufeh, Proc. of 3rd Int'1. Conf. on Thermionic Electrical Power Generation, Jülich, Germany (June 1972), Vol. 3, p. 1091.

6. S. Weber, "Flectron Fmission and Design of Cesium-Oxide Cathodes", Doctoral Thesis, Technichen Hochschule Stuttgart (1964).

7. J. M. Houston, Advan. Electron. 17, 147 (1962).

8. N. S. Rasor, Rept. of Thermionic Conv. Specialist Conf., San Diego (Oct. 1971) p. 181.

9. N. S. Rasor and C. Warner, J. Appl. Phys. 35, 2589 (1964).

10. H. W. Wassmuth, Ann. d. Physik 26, 326 (1971). 


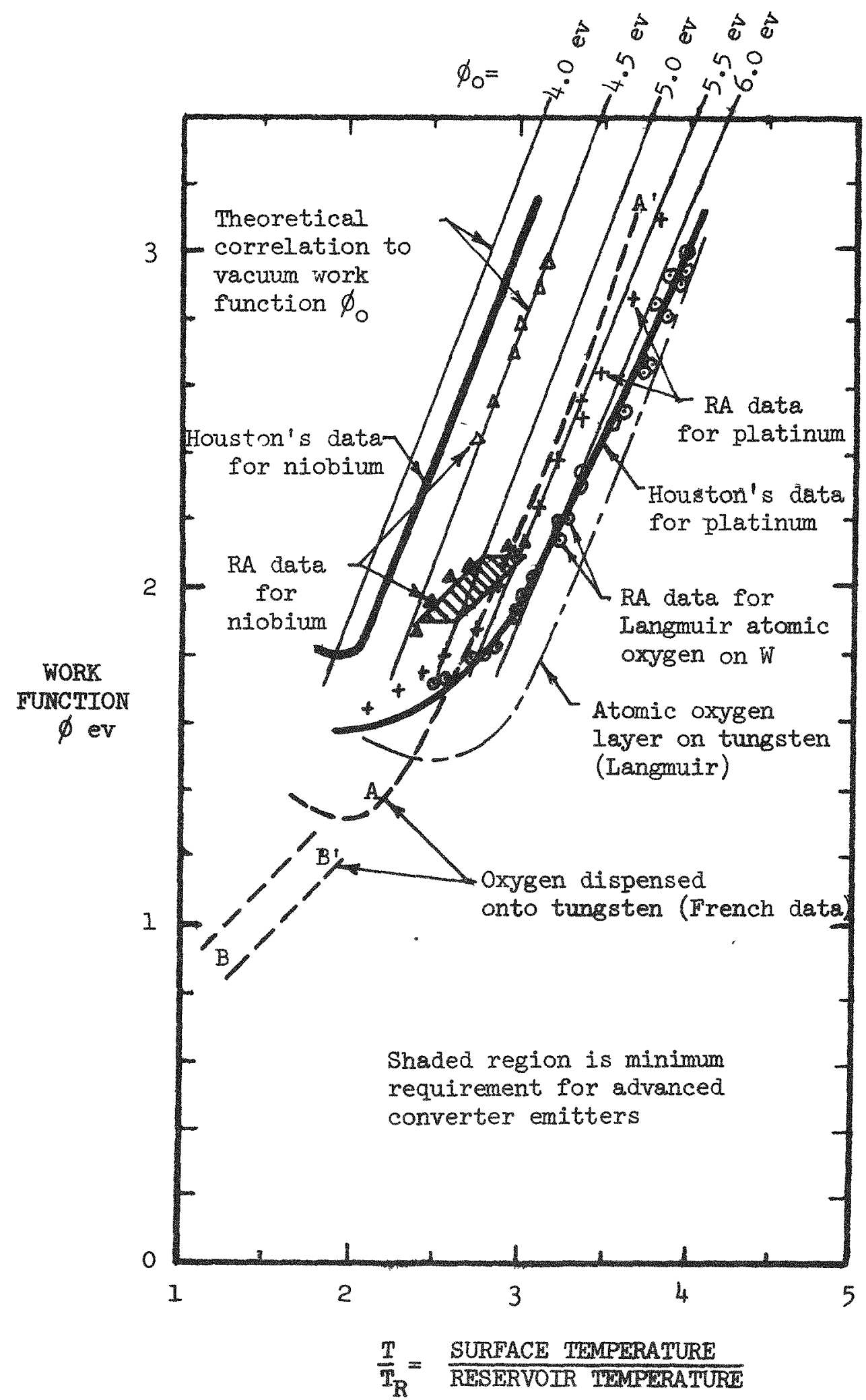

Fig. VII-I. Correlation plot characterizing observed data for various advanced emitter surfaces, and identifying the minimum requirements for advanced converter operation (shaded region). 


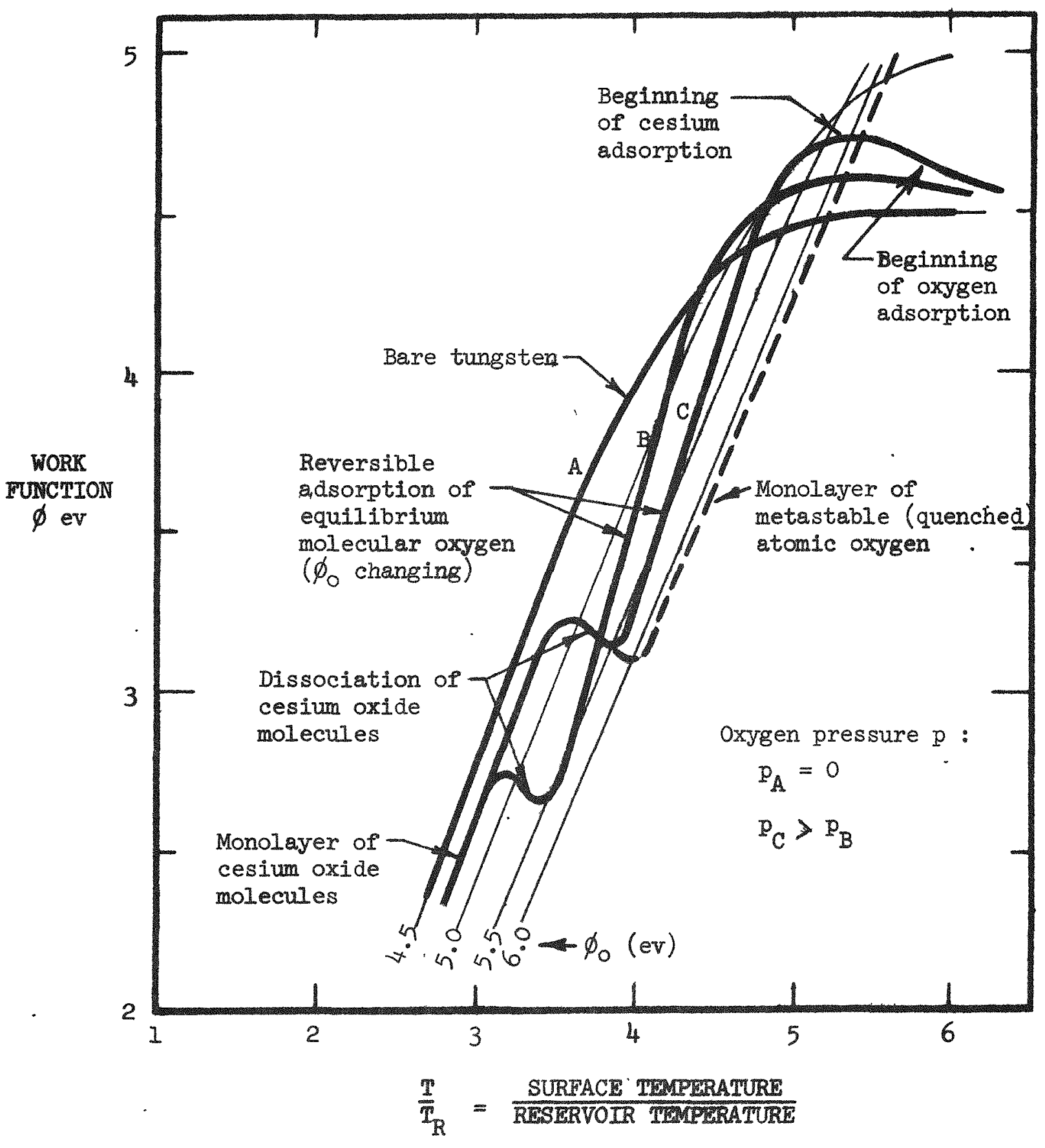

Fig. VII-2. Hlustrative representation of the dominant features of observed emission data for the $\mathrm{CS}=0-\mathrm{W}$ surface, and their tentative identification with specific physical states and processes. 